\title{
Interleukin-27 Functional Duality Balances Leishmania Infectivity and Pathogenesis
}

\begin{abstract}
Abdollah Jafarzadeh ${ }^{1,2}$, Maryam Nemati ${ }^{2,3+}$, Prashant Chauhan ${ }^{4 \dagger}$, Ashok Patidar ${ }^{4}$, Arup Sarkar ${ }^{5}$, Iraj Sharifi ${ }^{6}$ and Bhaskar Saha ${ }^{4,5 *}$

${ }^{1}$ Department of Immunology, School of Medicine, Kerman University of Medical Sciences, Kerman, Iran, ${ }^{2}$ Immunology of Infectious Diseases Research Center, Research Institute of Basic Medical Sciences, Rafsanjan University of Medical Sciences, Rafsanjan, Iran, ${ }^{3}$ Department of Haematology and Laboratory Sciences, School of Para-Medicine, Kerman University of Medical Sciences, Kerman, Iran, ${ }^{4}$ National Centre for Cell Science, Pune, India, ${ }^{5}$ Trident Academy of Creative Technology, Bhubaneswar, India, ${ }^{6}$ Leishmaniasis Research Center, Kerman University of Medical Sciences, Kerman, Iran
\end{abstract}

\section{OPEN ACCESS}

Edited by:

Paul Laszlo Bollyky,

Stanford University, United States

Reviewed by:

Parna Bhattacharya,

US Food and Drug Administration,

United States

Diego Luis Costa

Ribeirão Preto Medical School

(USP), Brazil

Felipe Passero

University of São Paulo, Brazil

Laís Amorim Sacramento,

University of São Paulo, Brazil

${ }^{*}$ Correspondence:

Bhaskar Saha

bhaskar211964@yahoo.com

tThese authors have contributed equally to this work

Specialty section:

This article was submitted to Microbial Immunology,

a section of the journal

Frontiers in Immunology

Received: 09 March 2020

Accepted: 15 June 2020

Published: 07 August 2020

Citation:

Jafarzadeh A, Nemati M, Chauhan $P$

Patidar A, Sarkar A, Sharifi I and

Saha B (2020) Interleukin-27

Functional Duality Balances

Leishmania Infectivity and

Pathogenesis.

Front. Immunol. 11:1573.

doi: 10.3389/fimmu.2020.01573
IL-27 is a cytokine that exerts diverse effects on the cells of innate and adaptive immune systems. Chiefly expressed in macrophages and dendritic cells during the early phase of Leishmania infection, IL-27 contributes to the protection against L. major infection but suppresses the protective Th1 response against $L$. donovani, $L$. infantum, L. amazonensis and L. braziliensis infections, suggesting its functional duality. During the late stage of Leishmania infection, IL-27 limits the immunopathogenic reactions and tissue damages. Herein, we analyze the mechanism of the functional duality of IL-27 in the resistance or susceptibility to Leishmania infection, prompting IL-27 for anti-Leishmanial therapy.

Keywords: EBI3, IL-27, Leishmania, p28, WSX-1

\section{INTRODUCTION}

IL-27 is a heterodimer of p28 and Epstein-Barr virus-induced gene 3 (EBI3) subunits and signals through IL-27-receptor complex, a heterodimer of IL-27R $\alpha$ WSX-1 and gp130 subunits (1). The major producers of IL-27 are activated antigen-presenting cells (APCs), including DCs and macrophages $(2,3)$. Signaling axes, including TLR4-MyD88-AP1/c-Fos, TLR4-MyD88-IRF1/IRF8-NF-kB-c-Rel, TLR3/TLR4-TRIF-IRF3/IRF7, IFN- $\gamma$-MyD88-IRF8, and IFN- $\alpha$ /IFN- $\beta$-STAT-1/STAT-2-IRF1/IRF9 induce the p28 expression (4-7). However, p38MAPK overexpression activates c-Fos that inhibits p28 expression $(2,8)$. By stimulating the C-Jun $\mathrm{N}$-terminal kinases (JNK), MAPKs, and the phosphoinositide-3-kinase (PI3K), signaling IFN$\gamma$ induces IL-27 expression in human monocytes (5). The EBI3 expression is induced by the signaling axes TLR2/TLR4/TLR9-MyD88-NF-kB/PU.1 (9-11) (Figure 1). Although IL-27 is secreted as p28-EBI3 heterodimers, the IL-27p28 subunit can be secreted without EBI3. p28 (or IL-30) may work as IL-27 antagonist while working through IL-27R $\alpha$ (12) but may work as an agonist through IL-6 receptor; the mechanism behind these contrasting effects remains unclear (13). The IL-27R $\alpha$ exhibits the cellular and tissue/organ specificity for IL-27 effector functions. Various cells including activated B cells, activated endothelial cells, DCs, macrophages, mast cells, monocytes, naïve $\mathrm{T}$ cells, NK cells, express $\operatorname{IL}-27 \mathrm{R}(12,14,15)$. The diversity of IL-27R-mediated intracellular functions depends on the activation of different isoforms of JAK and STAT present in the immune cell subsets: For instance, JAK-1, JAK-2, Tyrosine kinase-2 (TYK-2), STAT-1,-2,-3,-4, and -5 in naïve CD4 ${ }^{+}$T cells, JAK-1, STAT-1, STAT-3, and STAT-5 in NK cells, STAT-1 and STAT-3 in monocytes, and STAT-3 in mast 
cells (12). The binding of IL-27 to its receptor initiates the JAK/STAT signaling pathway (Figure 2), which involves phosphorylation of mainly STAT-1, STAT-3, and STAT-5 transcription factors (TFs) (16). The induction of SOCS3 (17), however, inhibits IL-27 signaling through a negative feedback loop, by inhibiting JAK-activity (18). By virtue of all these immunomodulatory functions, IL-27 plays significant roles in Leishmaniases, a complex of diseases inflicted by the protozoan parasite of the genus Leishmania, as described below.

\section{IL-27 FUNCTIONS IN INNATE AND ADAPTIVE IMMUNE SYSTEMS}

Upon stimulation with TLR ligands, IFNs and CD40-ligand, DCs, and macrophages release IL-27 that work in an autocrine and paracrine manner to mount innate and adaptive immune responses in several diseases; by contrast, many pathogens induce the synthesis of IL-27 in these cells.

\section{Effects of IL-27 on Innate Immunity}

IL-27 promotes NK cell cytotoxicity through upregulation of perforin and granzyme B expression (2) and supports the IFN$\gamma$ production by inducing T-bet, a transcription factor, and by enhancing the IL-18 responsiveness (19). IL-27 treatment of mast cells and eosinophils enhances their adhesion and survival and induces the production of pro-inflammatory cytokines such as IL-1, TNF- $\alpha$, and IL-6 (20). IL-27 limits neutrophil recruitment and reduces IL-6 and IL-12 secretion from these

Abbreviations: AhR, aryl hydrocarbon receptor; AP1, activator protein 1; APC, antigen presenting cell; CCR, C-C chemokine receptor; CL, cutaneous Leishmaniasis; CTLA-4, cytotoxic T-lymphocyte-associated antigen 4; CXCL, chemokine (C-X-C motif) ligand; DC, dendritic cell; DCL, diffuse cutaneous Leishmaniasis; EBI3, Epstein-Barr virus-induced gene 3 (EBI3) subunits; ERK, extracellular signal-regulated; GAS, gamma interferon activation site; IDO, inoleamine-2,3-dioxygenase; IFN, interferon; IKK, I kappa B kinase; IL, interleukin; ILCs, innate lymphoid cells; iNOS, inducible nitric oxide synthase; IRAK, interleukin-1 receptor-associated kinase 4; IRF, interferon regulatory factor; ISRE, interferon-sensitive response element; JAK/STAT, Janus kinase/signal; transducers and activators of transcription; JNK, Janus kinase; LPS, lipopolysaccharide; LRR, leucine-rich repeats; MAL, MyD88 adaptor-like protein; MAPK, mitogen-activated protein kinases; MCL, mucocutaneous Leishmaniasis; MHC, major histocompatibility complex; MIP, macrophage inflammatory proteins; MKK, mitogen-activated protein kinase; moDCs, monocyte-derived dendritic cells; MyD88, MYD88 innate immune signal transduction adaptor; NAP-1, nucleosome assembly protein; NET, neutrophil extracellular traps; NF- $\mathrm{KB}$, nuclear factor Kappa-light-chain-enhancer of activated B cells; NK cells, natural killer cells; NKT, natural killer T cells; NO, nitric oxide; NOX, nicotinamide adenine dinucleotide phosphate (NADPH) oxidase; p38MAPK, P38 mitogenactivated protein kinases; PAMPs, pathogen-associated molecular patterns; PD1, programmed cell death protein 1; PD-L2, programmed cell death ligand 2; PI3K, phosphoinositide 3-kinase; PKDL, post-kala-azar-dermal Leishmaniasis; PKDL, Post-kala-azar dermal Leishmaniasis; PKR, protein kinase R; PRR, pattern recognition receptors; RNI, reactive nitrogen intermediates; ROR $\gamma \mathrm{T}$, RARrelated orphan receptor gamma; ROS, reactive oxygen species; SOCS, suppressor of cytokine signaling; STAT, signal transducer and activator of transcription; $\mathrm{TAB}$, TAK1 binding protein; TAK1, transforming growth factor beta-activated kinase 1; T-Bet, T-box transcription factor; TBK-1, tank binding kinase-1; TCCR, T-cell cytokine receptor; TGF, transforming growth factor beta; TLR, toll-like receptor; TNF- $\alpha$, tumor necrosis factor alpha; TRAM, TRIF-related adaptor molecule; TRIF, TIR-domain-containing adapter-inducing interferon- $\beta$; VL, visceral Leishmaniasis. cells (21). IL-27 enhances the differentiation of monocytes into macrophages, stimulates macrophages to produce nitric oxide, and induces moDCs to express IL-27, IL-8, CXCL10, chemokine receptor (CCR1), IRF8, and IFN-stimulated genes (3). IL-27-pretreated monocytes show activated STAT-3 and NF- $\kappa$ B phosphorylation, elevated TLR4 expression, and with LPS co-treatment, increase IL-6, TNF- $\alpha$, MIP- $1 \alpha$, and MIP- $1 \beta$ expression (22). By contrast, IL-27 induces the expression of the immunosuppressor indoleamine 2,3-dioxygenase (IDO) in humans monocytes $(18,23)$.

IL-27 inhibits DC functions, as WSX-1-deficient DCs are hyper-reactive to LPS and promote NK cells and T cells to produce higher amounts of IFN- $\gamma$ than that induced by wild-type DCs (24). IL-27 pre-treatment of DCs reduces the LPS-stimulated expression of the MHC-II and costimulatory molecules-CD40, CD86-perhaps due to IL-27-induced elevated CD39 expression $(24,25)$. B7-H1 (PD-L1), which provides suppressive signals to T cells, is upregulated by IL-27 in DCs $(10,26,27)$. Consistent with these observations, IL27 reduces HLA-restricted antigen presentation and inhibits proliferation and cytokine production of allogeneic T cells (28). Through STAT-1 activation (29), IL-27 inhibits proliferation and cytokine production by type-2 Innate lymphoid cells (ILC2)a specialized cell-type that lacks antigen-specific receptors but produces high levels of helper T-cell cytokines and lipid mediators in response to antigen-independent stimuli. ILC2 express GATA3 and partake in airway inflammation via the production of type- 2 cytokines. A summary of the effects of IL-27 on innate immune cells is shown in Figure 3A.

\section{Effects of IL-27 on the Adaptive Immune System}

Naïve CD ${ }^{+}{ }^{+}$cells abundantly express IL-27R $\alpha$ or WSX-1, but IL-2 activated and differentiated $\mathrm{CD} 4^{+} \mathrm{T}$ cells show reduced IL-27R $\alpha$ expression (30). IL-27 induces T-bet and IL-12R $\beta 2$ expression in $\mathrm{CD}^{+} \mathrm{T}$ cells imparting IL-12 responsiveness during the early phases of Th1 polarization (Figure 2) (31). By contrast, IL-27 inhibits IL- 2 production from $\mathrm{CD}^{+}{ }^{+}$Th cells through SOCS3 induction, limiting T cell responses, and as IL2 is responsible for the proliferation and survival of Th1 cells, IL-27 mediates suppression of Th1 cell-related immunity (32). Suppression of Th1 cell response by IL-27 also can be explained by the induction of IL-10 an anti-inflammatory cytokine (33). IL-27 inhibits Th2 cell development and production of Th2 cytokines in already polarized Th2 cells by downregulation of GATA3 expression and upregulation of T-bet expression (34). IL- 6 and TGF- $\beta$ trigger naïve $\mathrm{CD}^{+} \mathrm{T}$ cells differentiation to Th17 cells by inducing ROR $\gamma \mathrm{t}$ expression (35). IL-27 inhibits the Th17 cell differentiation through interference with IL-6 signaling and suppression of the expression ROR $\gamma$ t, induction of the IL10 production and autocrine IL-10-mediated inhibition, and induction of programmed death-ligand 1 (PD-L1) on naïve $\mathrm{T}$ cells $(36,37)$.

Two subsets of Treg cells are generated from precursor cells in the thymus including natural Treg (nTreg) and inducible Treg (iTreg) cells, or antigen-induced naive $\mathrm{CD}^{+} \mathrm{T}$ cells in 


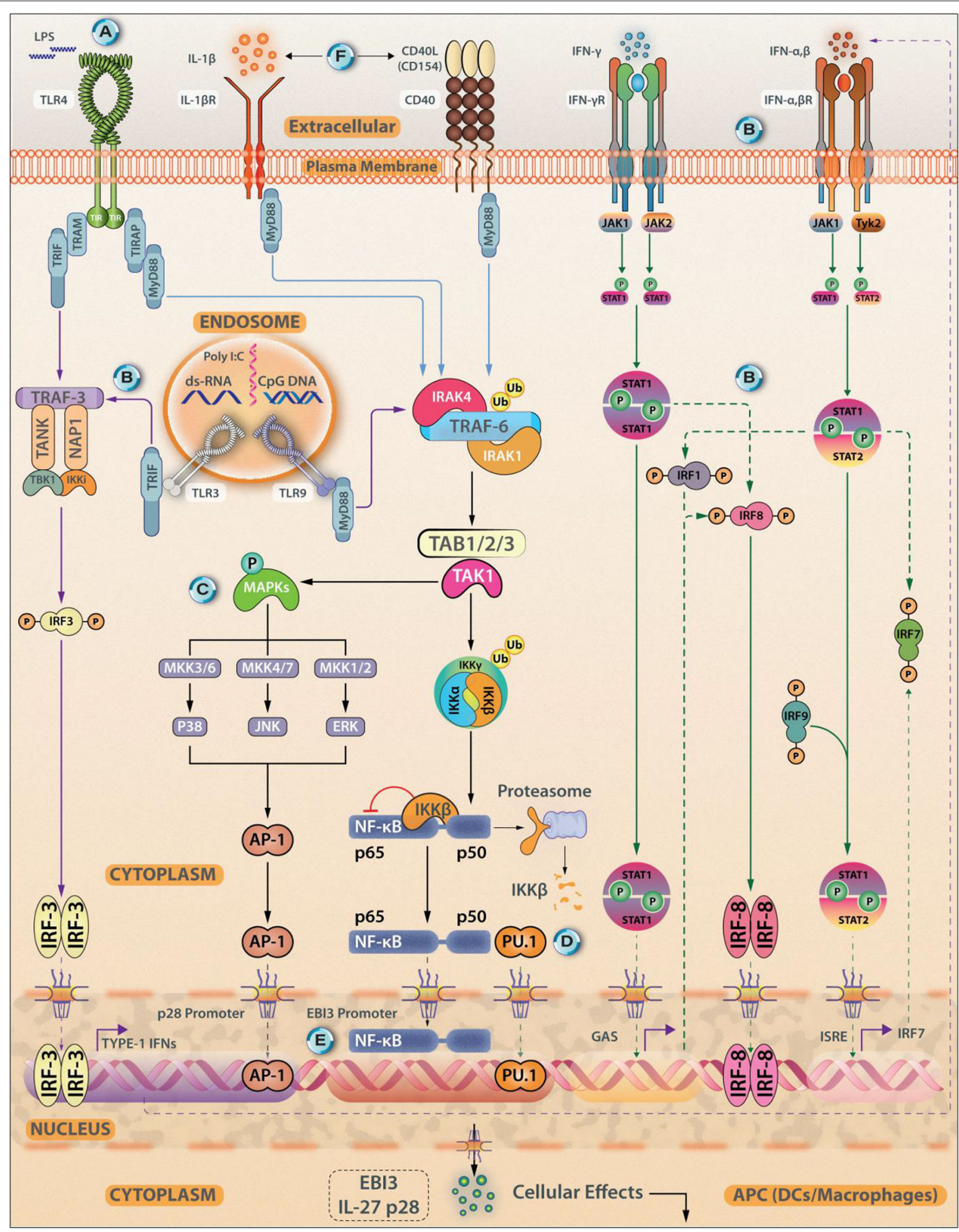

FIGURE 1 | Transcriptional Control of IL-27 Synthesis. Antigen experienced immune cells (APCs, DCs, and macrophages) act as sources of IL-27. Various cellular receptors such as Toll-Like Receptors (TLR4), IL-1 $\beta$ R, and CD40 promote IL-27 synthesis. The expression of IL-27 subunits from APCs can be induced using TLR 
FIGURE 1 | agonists Poly(l:C), lipopolysaccharide (LPS), and CpG-DNA, for TLR3, TLR4, and TLR9, respectively. (A) The expression of the IL27p28 subunit can be induced through signals coming from the TLR4/MyD88/AP-1/C-Fos signaling axis. (B) Other signaling axes that culminate in the induction of IL-27p28 synthesis areTLR3/TLR4-TRIF-IRF3/IRF7; IFN- $\gamma$ /MyD88/IRF8 and IFN- $\alpha /$ IFN- $\beta$-STAT1/STAT2-IRF1/IRF9. (C) IFN- $\gamma$ can induce IL-27 expression via stimulating JNK, MAPKs, and PI3K signaling. (D) EBI3 expression is induced by signaling through TLR2/TLR4/TLR9-MyD88-NF-KB/PU.1. (E) Both p50 and p65 can bind to the EBI3 promoter. (F) Exogenous stimuli from IL-1 $\beta$ R or CD40-CD154 ligation can also trigger IL-27 synthesis in a MyD88 dependent fashion. Besides NF-kB, C-Rel, recruitment of PU.1, and IRF1 and IRF3 are essential events that regulate IL-27 synthesis by shaping its transcriptional landscape. Both IFN- $\gamma$, along with IFN- $\alpha$ and IFN- $\beta$ are reported to be associated with p28 expression in DCs.

the presence of TGF- $\beta$ and IL-2, in the peripheral tissues, respectively. Treg cells express the transcription factor FoxP3 and are characterized by the secretion of immunosuppressive cytokines TGF- $\beta$, IL-10, and IL-35 (38). The iTReg were divided into two subgroups, including Tr1- and Th3-cells, which are characterized by the production of the large amounts of IL10 and TGF- $\beta$, respectively (39). Indeed, IL-27 supports the development of immune-regulatory $\operatorname{Tr} 1 \mathrm{CD}^{+} \mathrm{T}$ cells (40). IL27 also promotes the development of IL-10, producing T-bet ${ }^{+}$ CXCR $^{+}{ }^{+}$Treg cells (41). IL- 4 and TGF- $\beta$ elicit naïve CD $4^{+} \mathrm{T}$ cells differentiation to Th9 cells, which express the transcription factor PU.1 and secrete large amounts of IL-9 that contribute to mast cell activation, induction of allergic reactions, and immune responses to intestinal helminth infections (42). IL-27 inhibits the development of Th9 cells (43). IL- 6 and IL-21 elicit the T follicular helper (Tfh) cell differentiation from naïve $\mathrm{CD} 4^{+} \mathrm{T}$ cells. Tfh cells express Bcl6-a transcription factor-and provide CD40L, ICOS, and IL-21 signals required for B cell proliferation and differentiation (44). IL-27 promotes Tfh cell polarization and induces IL-21 (45), which promotes B cell expression of Bcl-6 and Blimp-1 that are critical for plasma cell differentiation and B cell function. Although IL-27 induces B cell proliferation and antibody production, it does not seem to promote the formation of memory B cells (46).

$\mathrm{CD}^{+} \mathrm{T}$ cells recognize viral- and tumor-derived antigenic peptides presented by MHC-I molecules and play a fundamental role in the killing of virally infected and cancer cells. IL27 enhances the proliferation of naive $\mathrm{CD} 8^{+} \mathrm{T}$ cells and the production of IFN- $\gamma$ and granzyme B (47) (Figure 2). IL-27 thus differentially affects the functions of immune cells in both innate and adaptive immune systems. The effects of IL-27 on adaptive immune cells is summarized in Figure 3B.

\section{THE ROLE OF IL-27 IN LEISHMANIA INFECTION}

Leishmania is a protozoan trypanosomatid parasite and is transmitted by the sand fly vectors. Leishmania exists as extracellular, flagellated motile promastigotes in sand flies and as sessile, aflagellate, amastigotes within the mammalian macrophages in skin, liver, spleen, bone marrow, and mucosal tissues. It causes a complex of diseases called Leishmaniases to affect 12 million people worldwide and one billion at risk $(48,49)$. Depending on the invading specie of Leishmania, tissue tropism of the parasite, the site and the route of infection and pathophysiology, Leishmaniases are classified into cutaneous (CL), mucocutaneous (MCL), diffuse cutaneous (DCL), visceral
(VL), and post-kala-azar dermal Leishmaniasis (PKDL) (49). The CL is the most prevalent form of the disease $(70-75 \%)$, caused by L. major and L. tropica in the Middle East and North Africa, while $L$. mexicana and $L$. braziliensis are predominant in South America $(49,50)$. L. amazonensis causes DCL and CL with disseminated lesions. L. donovani and L. infantum cause VL that disseminates to spleen, liver, and bone marrow (51). Thus, Leishmania species differ in their growth kinetics, the tissue of infection, and clinical outcomes. Although macrophages serve as the host for all these Leishmania sp. the immunopathology of Leishmania is greatly affected by tissue-specific non-immune cells. IL-27 plays a complex role in the immuno-pathology of Leishmaniasis (52).

\section{Do Leishmania Salivary Gland Proteins (SGPs) Affect IL-27 Secretion?}

Most species of Leishmania are transferred through the phlebotomine sand-fly vector. The metacyclic promastigotes are embedded in proteophosphoglycan-rich promastigote secretory gel (PSG) secreted by themselves in the anterior midgut of sandflies. PSG must be regurgitated along with infective promastigotes before sand flies can begin hematophagy on host skin. In turn, this event leads to the accumulation of PSG, Leishmania along with sand-fly saliva containing SGPs on host skin. Since the first description of sand-fly SGPs diseaseexacerbating function in CL (53), these are shown to induce cytokines and chemokines with potential contrasting functions (54). Many proteins including LJM19, a novel $11-\mathrm{kDa}$ protein, are identified as anti-Leishmanial vaccine candidates $(55,56)$. Although IL-27-inducing SGPs are not reported, some probable pathways may be proposed. First, as the sand-fly bite is rich in immunomodulatory components like CD39 family ecto-apyrases converting ATP and ADP to AMP and Pi (57), the adenosine receptors on the infected DC and macrophages may modulate IL27 secretion (58). Second, as platelet activation is associated with the chemotactic migration of effector monocytes, a potent source of IL-27, to the sites of L. major infection (59) an axis of SGPsplatelets activation-monocyte recruitment may modulate IL-27 production affecting the outcome of Leishmania infection. Third, salivary-homogenates from Lutzomiya longipalpis suppress the costimulatory molecule expression and CD40L-induced DCs maturation (60), which may lower available IL-27 pools as observed with IL-10 and TNF- $\alpha$. A limitation with such studies is that these do not highlight the exact specific composition of sand-fly salivary gland extracts, which may be composed of more than 35 secreted proteins (61). Fourth, although a vasoactive peptide (maxadilan) from the L. longipalpis saliva is shown to indeed increased production of prostaglandin E2 $\left(\mathrm{PGE}_{2}\right)$ 


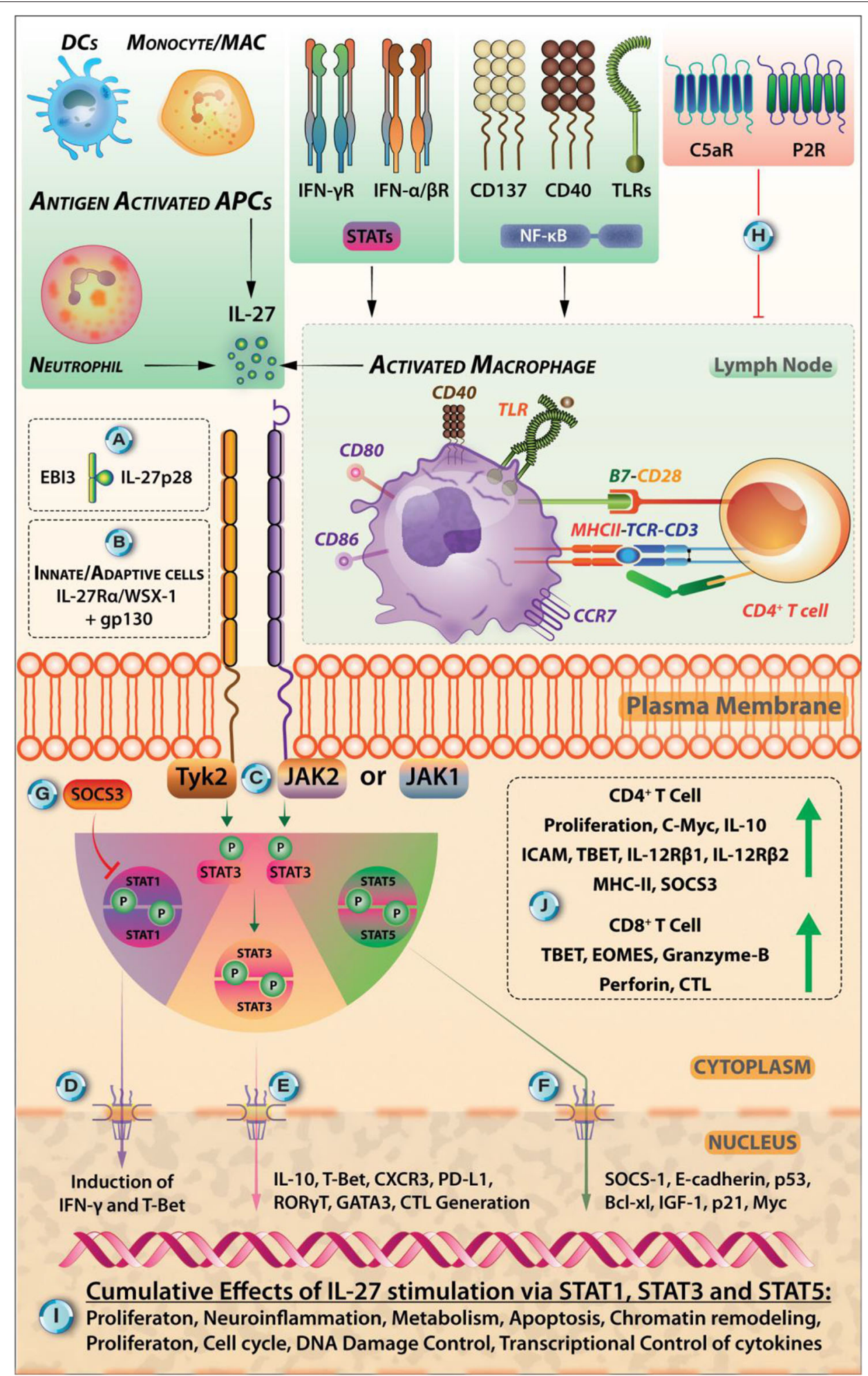

FIGURE 2 | Various Extracellular Cues Can Induce IL-27 Signaling In STAT-1, STAT-3, AND STAT-5 Dependent Manner. (A) IL-27 is heterodimeric cytokine comprised of p28 and Epstein-Barr virus-induced gene 3 (EBI3) subunits. (B) IL-27 exerts its specific effects in immune cells through binding to its receptor IL-27R (comprised of 
FIGURE 2 | WSX-1/IL27R $\alpha$ and gp130). (B) IL-27R is expressed by cells belonging to both innate and adaptive modules of the immune system. (C) The intracellular signaling is initiated when IL-27 binds to its receptor, and this triggers the signal flow through kinases JAK1, JAK2, and Tyrosine kinase (Tyk2) that phosphorylates the subsequent isoforms of STAT proteins (mainly STAT-1, STAT-3, STAT-4, and STAT-5 each of which, has restricted expression in various immune cells) and promote their dimerization and subsequent nuclear translocation. (D) The nuclear translocation of STAT-1 dimers can lead to the induction of IFN- $\gamma$ signaling and transcription factor T-bet that induces Th1 cells. (E) However, nuclear translocation of STAT3-dimers leads to the synthesis of IL-10, CXCR3, cytotoxic T lymphocyte induction, GATA-3, RORyt that may promote Th2, Th17 responses (not necessarily under the effects of IL-27). (F) Signaling through STAT-5-its dimerization, nuclear translocation, and DNA binding through tyrosine phosphorylation - can lead to the upregulation of SOCS-1, E-cadherin, p53, Bcl-xL, p21, and Myc proteins. (G) The signals through IL-27R are carefully regulated in the cell via its intrinsic regulation through SOCS-1 and SOCS-3, maintaining a negative feedback loop. (H) The extracellular cues coming from extracellular ATP binding to purinergic receptors (P2R) in the case of inflammation and C5a binding to C5aR are antagonistic signals for IL-27 synthesis. (I) Broad effects of IL-27 relating to proliferation, in regulating cell cycle, neuroinflammation, metabolism, apoptosis, chromatin remodeling, and transcriptional control are mediated by STAT-1, STAT-3, and STAT-5 signaling pathways. (J) IL-27 stimulation in CD4+ T cells leads to their proliferation, expression of C-Myc, IL-10, ICAM, T-bet, IL-12R $\beta 1$, IL-12Rß2, MHC-II, and SOCS3. It also promotes the STAT1-, STAT3-dependent generation of IL-10 secreting Tr1 cells. IL-27 promotes CD8 ${ }^{+}$CTL generation, causes upregulation of T-bet, Eomesodermin (EOMES), and Granzyme-B. IL-27-induced modulation of host-pathogen relationships is an area described in this review in the context of protozoan parasite Leishmania.

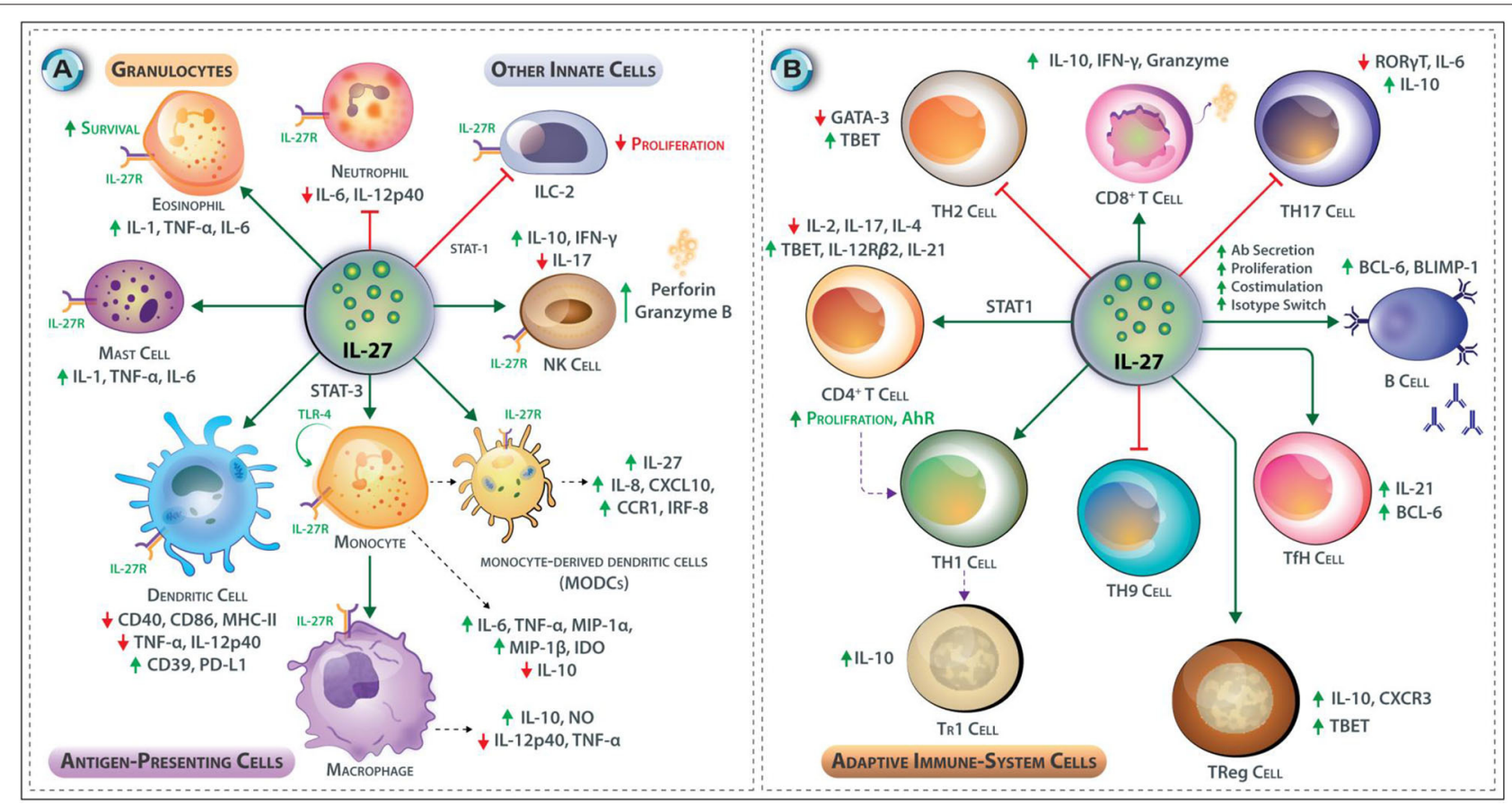

FIGURE 3 | (A,B) Effects of IL-27 on Innate and Adaptive immune responses. (A) IL-27 promotes cytotoxicity in NK cells through upregulation of perforin and granzyme B, and it induces IFN- $\gamma$ production from NK cells via T-bet transcription factor but inhibits IL-17 production in NK cells. In mast cells and eosinophils, IL-27 promotes pro-inflammatory cytokine synthesis and release; these include IL-1, TNF- $\alpha$, IL-6, promotes adhesion and survival in eosinophils. Contrary, IL-27 limits neutrophil recruitment and reduces the secretion of IL-6 and IL-12p40 from these cells. IL-27 enhances TLR4 expression by monocytes through STAT-3 and NF-KB and enhances their differentiation to macrophages. In macrophages, it induces NO expression and triggers moDCs to express IL-27, IL-8, CXCL10, CCR1 IRF8, and IFN-stimulated genes. IL-27 also induces the expression of an immunosuppressive enzyme IDO in human monocytes. IL-27 inhibits DC functions; stimulation of DCs with IL-27 before LPS reduces expression of CD40, CD86, and MHC-II but upregulation of CD39 and PD-L1. IL-27 may also inhibit the secretion of TNF- $\alpha$ from DCs. IL-27 inhibits the innate lymphoid cells (a subgroup of innate cells that lacks specific antigenic receptors) proliferation through STAT-1. (B) IL-27 induces T-bet and IL-12R $\beta 2$ expression in CD4+ $\mathrm{T}$ cells at the early phase of T cell polarization. IL-27 inhibits the production of IL-2 by CD4+ Thelper cells through induction of SOCS-3. IL-27 promotes IL-10-producing Tr1 cells. IL-27 inhibits the development of Th2 cells by downregulating GATA-3. IL-27 interferes with Th17 development by suppression of RORyt and interfering with IL-6 signaling it also stimulates IL-10 production and induction of PD-L1 on naiive T cells. IL-27 inhibits the development of Th9 cells. IL-27 supports the development of Tr1 CD4 ${ }^{+} \mathrm{T}$ cells. IL-27 also promotes the development of IL-10 secreting T-bet ${ }^{+} \mathrm{CXCR}^{+}{ }^{+}$Treg cells. T follicular helper (Tfh) cells produce IL-21 in the presence of IL-27. CD8 ${ }^{+} \mathrm{T}$ cells are also affected by the presence of IL-27 as it increases their proliferation and capacity to secrete IFN- $\gamma$, and granzyme B. IL-27 regulates many aspects of B cell development and their functions. In response to IL-27, B cells increase expression of Bcl-6 and Blimp1, which is critical for plasma cell differentiation.

(62) and reciprocally modulate TNF- $\alpha$ and IL-6 production from $\mathrm{BALB} / \mathrm{c}$ macrophages in a $\mathrm{PGE}_{2}$-dependent manner (62), the regulation of IL-27 by maxadilan and a correlation between $\mathrm{PGE}_{2}$ and IL-27 in experimental Leishmaniasis require further investigation. Similarly, SP15-like protein, D7-related proteins, lufaxin (reversible inhibitor of factor Xa of coagulation cascade), palmitoyl-hydrolase, and YRP proteins (57) may modulate the host IL-27 production by previously unexplored 


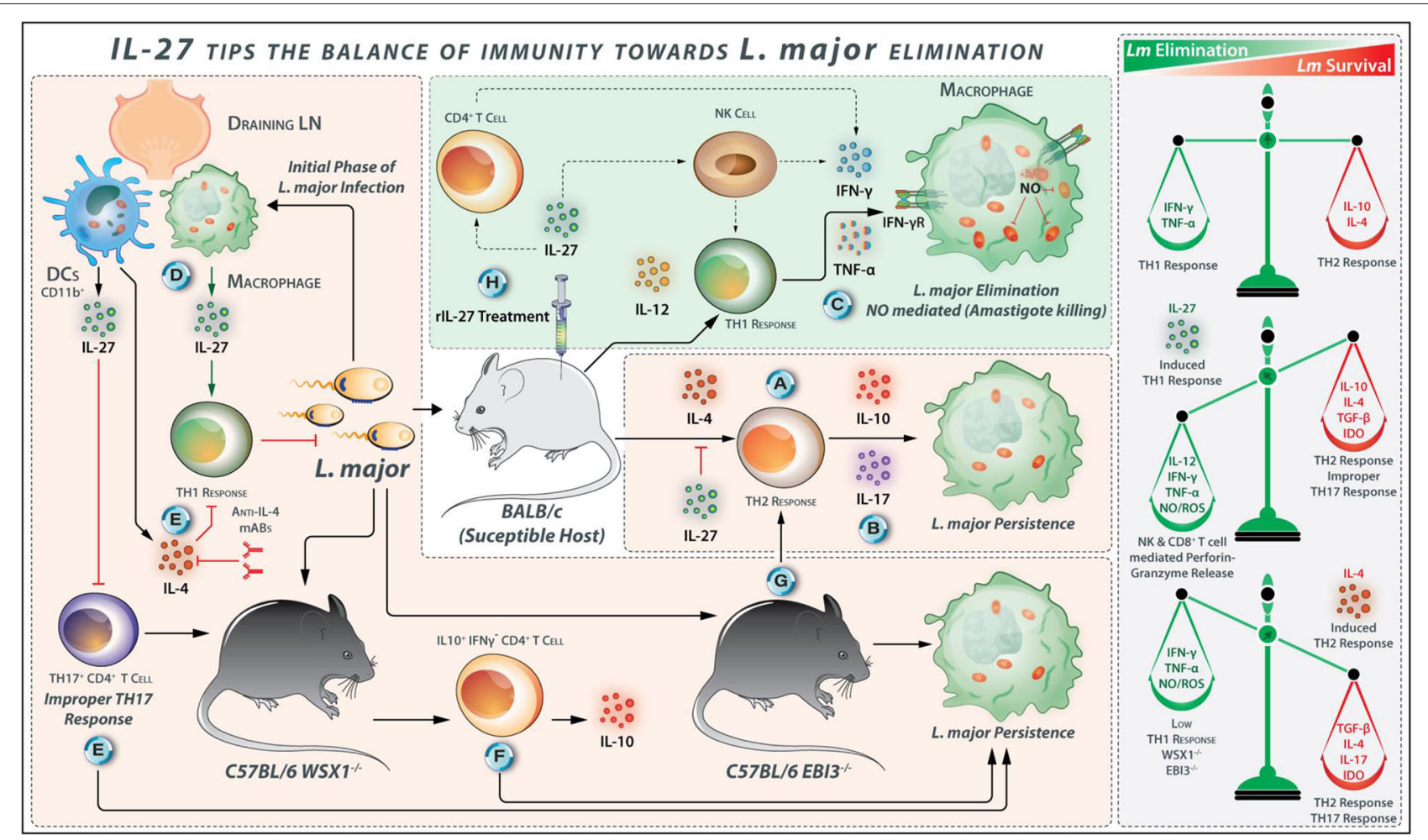

FIGURE 4 | IL-27 Tips the Balance of Immunity Toward L. major Elimination. (A) Promotion of L. major growth by Th2 response- IL-10 and IL-4 are identified as a factor for susceptibility in BLAB/c mice because these cytokines are drivers of Th2 type response, which promotes $L$. major growth. (B) Repression of IL-10 signaling increases IL-17 production and exacerbates $L$. major infection. (C) However, TNF- $\alpha$ and IFN- $\gamma$ cumulatively induce iNOS expression in $L$. major-infected macrophages for parasite clearance. (D) IL-27 is identified as a factor that promotes resistance to $L$. major infection in mice. L. major-infected CD11 b+ DCs are major sources of IL-27 secretion in the draining lymph nodes of C57BL/6. (E) In WSX1-1- mice, the initial immune response is accompanied by secretion of IL-4 by L. major-infected cells, and IL-4 neutralization during the early phase of infection may abolish the requirement of IL-27 for the development of an effective Th1 response. The role of IL-27 in the prevention of improper IL-17 cell development is also mentioned. (F) In WSX1- $1^{-1-}$ mice, the low percentage of IL-10 ${ }^{+} \mathrm{IFN}-\gamma^{-} \mathrm{CD} 4^{+} \mathrm{T}$ cells - associated with the development of more severe lesions - are found. (G) Similarly, in EBI3-/- mice, the Th1/Th2 balance is diverted toward Th2 response indicating the protective roles that IL-27 plays for immunity against $L$. major. $(\mathbf{H}) \mathrm{IL}-27$ stimulates $\mathrm{CD} 4^{+}$T cells and NK cells to secrete IFN- $\gamma$ during the early stages of $L$. major infection. Therefore, exogenous delivery of IL-27 into L. major-infected BALB/c mice exhibits protection by direct suppression of Th2 response and induces protective Th1 response.

mechanisms. More research is needed to confirm the definitive roles of salivary gland homogenates in immunosuppression and interception of the IL-27 secretion axis in the case of Leishmania sp. infection.

\section{The Role of IL-27 in L. major Infection}

L. major infection results in polarization of the Th cells to either IL-12-dependent host-protective IFN- $\gamma$ secreting Th1 cells or IL4-dependent disease-promoting IL-10 and IL-4 secreting Th2 cells in resistant or susceptible mouse strains, respectively (63). The L. major-infected BALB/c mice display high IL-17 levels, and IL-17 deficiency or IL-17 neutralization results in a reinforced host-protective anti-Leishmanial response (64). Likewise, IL-17 quantities are positively associated with skin inflammation in patients with CL and MCL (65). IFN- $\gamma$ and TNF- $\alpha$ synergistically induce the expression of inducible nitric oxide synthase (iNOS) that catalyzes nitric oxide production in macrophages to eliminate Leishmania $(65,66)$. The iNOS-deficient mice are vulnerable to $L$. major infection despite the presence of robust Th1 cell response, indicating an essential role of NO in limiting
Leishmania infection $(63,67)$. Adding the effects of IL-27 in these complex inter-regulated circuits develops a better understanding of the CL. High levels of IL-27 expression are observed in $L$. major infection in vivo. The p28 expression increases at the second week, whereas EBI3 expression becomes measurable in the fifth week in the L. major-infected C57BL/6 mice (68). $\mathrm{CD}_{11}{ }^{+}$DCs express both IL-27 subunits, including p28 and $\mathrm{EBI} 3$, in the draining lymph nodes of L. major-infected C57BL/6 mice at $24 \mathrm{~h}$ post-infection (69) (Figure 4). Therefore, the infected DCs are the major producers of IL-27 during the early phase of CL.

\section{IL-27 Treatment Suppresses Th2 Responses and Protects the Host From $L$. major Infection}

The IL-27 signaling via WSX-1 contributes to protection against L. major infection (69-71). Upon IL-27 treatment, IL27 transgenic mice are protected against L. major infection (34). The daily IL-27 administration during the first seven days after L. major infection of $\mathrm{BALB} / \mathrm{c}$ mice reduces the parasite load 
and increases the survival rate compared with control mice (34). The lymph node cells from $L$. major-infected IL-27-treated $\mathrm{BALB} / \mathrm{c}$ mice secrete higher quantities of IFN- $\gamma$ and produce lower amounts of IL-4 in comparison with the cells from control mice (34). Therefore, the exogenous IL-27 protects $L$. majorinfected BALB/c mice from CL by direct suppression of the Th2 cell responses accompanied by the induction of host-protective Th1 cell responses, perhaps due to its ability to augment IFN- $\gamma$ production from $\mathrm{NK}$ and $\mathrm{CD}_{4}^{+} \mathrm{T}$ cells $(70,71)$. The L. majorinfected macrophages from patients with healing forms of lesion produce a higher amount of IL-27 and IL-23 as compared with patients having non-healing forms of the lesion, suggesting that IL-27 and IL-23 may play synergistic roles with Th1 cytokines in protection against Leishmaniasis (72). L. major lysate-stimulated lymphocytes from EBI3 ${ }^{-/}$mice secrete fewer IFN- $\gamma$ and high IL-4, IL-10, and IL-13 as compared to the lymphocytes from the control mice on the second and third week post-infection. Thus, at early time points after infection, the Th1/Th2 cell balance in $\mathrm{EBI}^{-/-}$mice is diverted toward Th2 cells (69).

\section{IL-27 Deficiency Impairs Host-Protective Th1 Responses and Induces Susceptibility to L. major Infection}

In WSX $-1^{-/}$mice both IFN- $\gamma$ production and resistance to L. major are impaired $(69,71)$. EBI3 ${ }^{-/-}$C57BL/6 mice also display greater susceptibility to $L$. major infection compared to $\mathrm{C} 57 \mathrm{BL} / 6$ wild-type mice, with the maximum differences in the parasites loads and lesion sizes at the sixth-week postinfection; the lesions and parasite load are reduced from the eighth week, and lesions are entirely resolved till 14th week in $\mathrm{EBI}^{-/-}$mice (69). Rechallenge of healed $\mathrm{EBI} 3^{-/-}$mice with L. major does not lead to the elicitation of the pathological symptoms, indicating that the expansion and persistence of the protective immunologic memory are not impaired in $\mathrm{EBI} 3^{-/-}$ mice (69). These observations suggest the importance of EBI3 for early control of parasite replication (Figure 4). Similarly, when compared with wild-type mice, the lymph node cells from WSX $-1^{-/}$mice produce fewer IFN $-\gamma$ initially but makes up the deficiency in the later stages of the infection. However, both WSX-1-/- and wild-type mice successfully control the parasite and resolve the cutaneous lesions (71). Susceptibility to L. major infection in WSX-1-/- mice is restricted to the initial stages of infection when a considerable level of IL-4 is produced (71). The anti-IL-4 mAb administration during the early stages of infection improves the IFN- $\gamma$-dependent host resistance in Leishmania infected WSX-1-/- mice. The treatment of the WSX-1 $1^{-/}$mice with blocking anti-IL-4 antibody also reduces the T. cruzi parasite burden and also increases the number of IL- $17^{+} \mathrm{CD} 4{ }^{+}$cells, indicating that IL- 4 inhibits the Th17 cell development in parasitic infections $(73,74)$. The initial IL-4 production during $L$. major infection determines the necessity for IL-27 in the induction of Th1 cell responses to limit the CL (Figure 4). However, IL-27 is not required to maintain an extended Th1 response during the later stages of L. major infection. Although WSX-1 $1^{-/}$mice show significant lesions at an early phase of infection, at later stages of infection it ultimately limit parasite loads and resolve the infection $(70,71)$. Accordingly, the increased susceptibility of $\mathrm{WSX}-1^{-/-}$mice to L. major is accompanied by the Leishmania-induced IL-4 production initially; therefore, blockade of IL-4 during the initial phase of infection abolishes the early requirement for IL-27 for the development of effective anti-parasitic responses. At 68 weeks post-infection, IFN- $\gamma$ production is increased, and the IFN- $\gamma /$ IL- 4 ratio shifts toward Th 1 cells in WSX-1-/- and wild type mice, which were accompanied by parasite killing and lesion resolution (69). The early EBI3 expression is vital for the quick generation of effective Th1 cell-mediated immunity, but healing and immunologic memory develop in an IL-27-independent manner (69).

\section{IL-27 Contributes to Early Development and Maintenance of Th1 Cells and Mediates Immunity Against L. major}

It is proposed that IL-27 is initially produced by the parasitestimulated phagocytes and skews Th1 response before IL-12 production is upregulated (75). Indeed, the IL-27-stimulated $\mathrm{T}$ cells express IL-12R and are then differentiated to Th1 cells in the presence of IL-12 in vivo (34). Early production of IL-27 may result in Th1 cell differentiation, and later on, maintained by IL-12 produced from L. major-infected DCs (76). Therefore, L. major-infected DCs sequentially produce IL27 and IL-12 to establish and maintain protective Th1 cellmediated protective immunity against this pathogen. Delayed IL-12 production during L. major infection may cause a delay in the initiation of Th1 responses (77). Indeed, WSX-1 expression diminishes in differentiated Th1 cells; contrastingly, IL-12R is still abundantly expressed in activated Th1 cells. Th1 cells from $\mathrm{WSX}^{-/-}$mice display normal IFN- $\gamma$ production in response to IL-12. Therefore, IL-27 is necessary for the early development of Th1 cells, and IL-12 is necessary for early differentiation, establishment, and full activation of Th1 cells. IL-27 causes Th1 cell differentiation through the induction of p38MAPK that upregulates T-bet. Moreover, it promotes the expression of ICAM-1/LFA-1 adhesion molecules to induce ERK1/2-related signaling pathways. Induction of both signaling pathways causes IL-12R $\beta 2$ expression, which promotes the Th1 differentiation and IFN- $\gamma$ production in the presence of IL-12 (2). WSX-1-related signaling also induces STAT-1dependent expression of T-bet and trigger IFN- $\gamma$ production (78), and WSX $-1^{-/-}$mice display defects in IFN- $\gamma$ expression (71). IL-27R-deficient mice exhibit enhanced Th2 cell-dependent asthmatic manifestations (79). Consequently, IL-27 determines the suppression of Th2 cell response. IL-27 inhibits Th2 cell differentiation and associated cytokine-production from fully activated Th2 cells (12). IL-27 also directly inhibits GATA-3 expression in a STAT-1-dependent pathway (80). IL-27 reduces GATA-3 expression while inducing T-bet expression even in polarized Th2 cells (34).

\section{Regulatory Effects of IL-27 During L. major Infection}

Severe lesions are reported in L. major-infected WSX-1 ${ }^{-/-}$mice, which were associated with the appearance of the IL- $17^{+} \mathrm{CD} 4^{+}$ cells, indicating a role for IL-27 in preventing the improper 


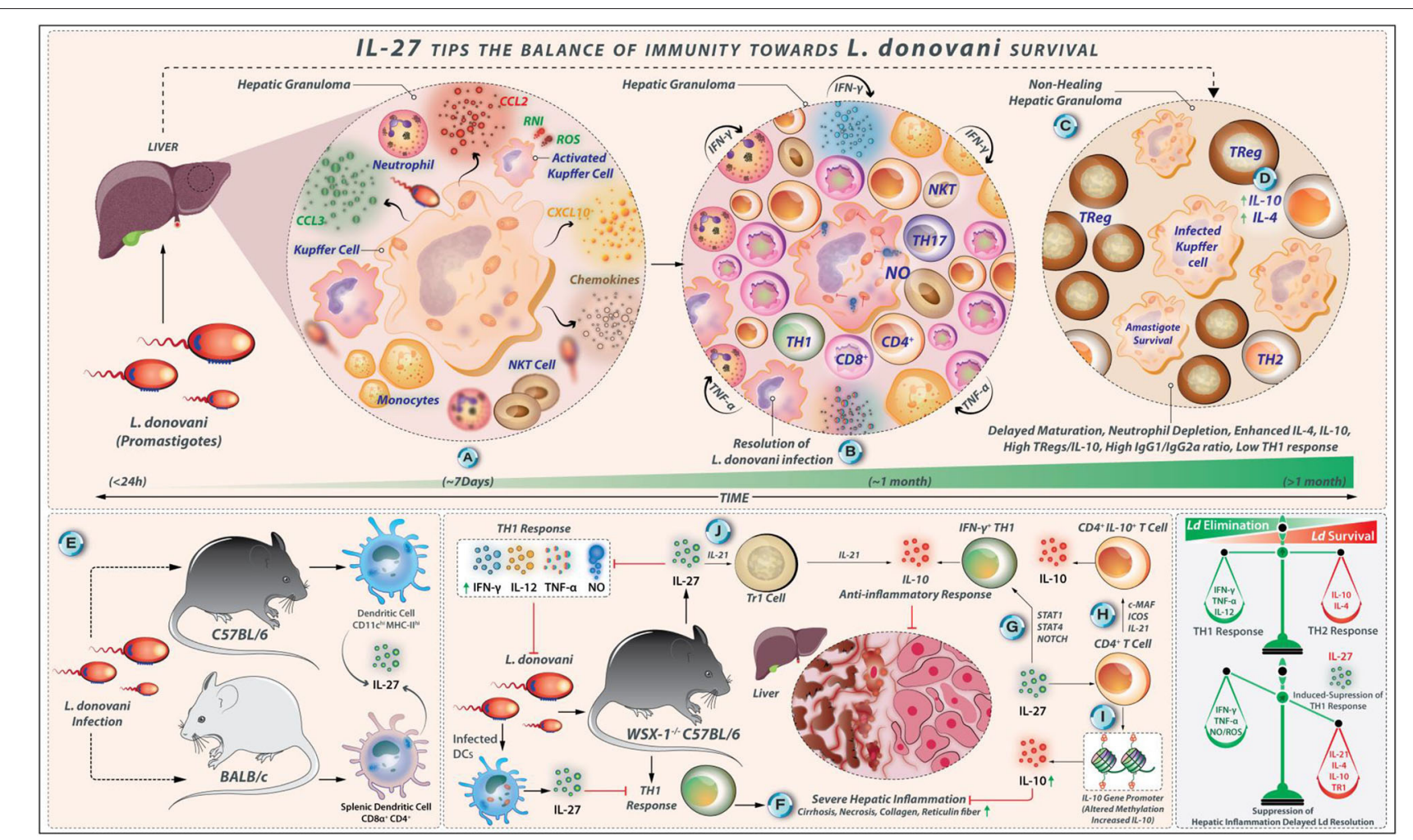

FIGURE 5 | IL-27 tips the balance of immunity toward L. donovani survival. (A) L. donovani amastigotes invade hepatic macrophages (Kupffer cells). This event is followed by the invasion of leukocytes, neutrophils, monocytes, and T cells under the influence of chemotactic factors like CCL3, CCL2, and CXCL3 secreted by infected Kupffer cells. (B) These immunological reactions lead to the formation of a granuloma that is abundant in pro-inflammatory factors (IFN- $\gamma$, TNF- $\alpha$, and $\mathrm{RNI} / \mathrm{ROS}$ secreted by Th1 cells, NK cells, and CD8 ${ }^{+} \mathrm{T}$ cells); under such conditions L. donovani infection is resolved over time. (C) However, the abundance of IL-4 and IL-10 decreased iNOS expression, high production of IgG1/lgG2a ratio, and delayed maturation of granuloma, depletion of neutrophils results in high parasite load. (D) Elevated IL-10 secreted by Treg cells also contributes to L. donovani survival. (E) Splenic CD11 hi $^{\text {MHC-II }}$ DCs from L. donovani-infected C57BL/6 mice show high levels of IL-27. Similarly, L. donovani infection in BALB/C mice produces IL-27. In this case, CD8 $\alpha^{+}$and CD4 ${ }^{+}$DCs are the major producers. (F) In WSX-1-/- C57BL/6 mice, a potent Th1 cell-linked response exhibits a severe hepatic inflammation (showing necrosis and deposition of reticulin fiber and collagen) that eventually resolves. In this context, IL-27-linked signals may suppress the Th1 response directly or indirectly, which helps in the suppression of hepatic inflammation by modulating the function of CD4 ${ }^{+} \mathrm{T}$ cells. (G) IL-27 supports the IL-10 production by IFN- $\gamma$ producing Th1 cells in a pathway that involves the induction of STAT-1, STAT-3, and NOTCH signaling. (H) The generation of CD4+ IL-10+ T cells by IL-27 requires the expression of c-Maf, ICOS, and IL-21. (I) IL-27 also alters methylation patterns in the IL-10-gene promoter in CD4+ T cells that increase IL-10 expression directly. (J) IL-27, along with IL-21, enhances the differentiation of IL-10 producing TR1 cells during VL.

development of Th17 cells during Leishmaniasis (68). The IL17-deficient BALB/c mice exhibit smaller lesions during L. major infection, although a modest reduction in their parasite load is observed (64). The addition of rIL-27 to L. major lysatestimulated $\mathrm{CD}^{+} \mathrm{T}$ cells collected at the eighth week postinfection from $L$. major-infected C57BL/6 mice enhances the population of IL- $10^{+}$IFN- $\gamma^{+} \mathrm{CD}^{+}$cells and IL- $10^{+}$IFN- $\gamma^{-}$ $\mathrm{CD}^{+}$cells. As compared with the wild-type C57BL/6 mice, WSX $-1^{-/-}$C57BL/6 mice display a low percentage of IL-10 ${ }^{+}$ IFN- $\gamma^{-} \mathrm{CD}^{+}$cells and more severe lesions 6 weeks after $L$. major infection (68). Therefore, the development of more severe lesions in the L. major-infected WSX-1-/- mice may partly be attributed to the downregulation of the anti-inflammatory cytokine IL-10. IL-27 does not interfere with IFN- $\gamma$, TNF- $\alpha$, or IL-17 production by the soluble Leishmania antigens (SLA)stimulated PBMCs from patients with CL and MCL. PBMC cultures from patients with CL and MCL when supplemented with IL-27 do not show any change in the production of IL10 (81). These findings indicate that the cytokine-producing cells from patients with CL and MCL are unresponsive to the regulatory effects of IL-27.

\section{IL-27 Is Dispensable for Maintaining Extended Protective Th1 Cell Response Against L. major}

IL-27 expressed by the infected-phagocytes and DCs during the early phase of $L$. major infection contribute to the protection during the initial stage of L. major infection, while considerable levels of IL-4 are present and IL-4-induced Th2 cell responses are dominant (82). The protective effects of IL-27 may be exerted through inhibition of IL-4 production, prevention of Th2 cell response (34), and induction of the IFN- $\gamma$ production from $\mathrm{CD}^{+}{ }^{+} \mathrm{T}$ and $\mathrm{NK}$ cells, which reinforces Th1 cell responses. However, IL-27 is not necessary to maintain an extended protective Th1 cell-related response during the late stage of 
L. major infection (70). IL-27 limits tissue damages and immunopathology during L. major infection via preventing the improper Th17 cell responses (68) and induction of the immunoregulatory cytokine IL-10. Based on the discussion above, the regulatory effects of IL-27 during L. major infection are compiled and summarized in Figure 4.

\section{The Role of IL-27 in L. donovani Infection}

A large number of the $L$. donovani-infected persons are asymptomatic because they develop an effective T-cell-mediated immune response against the parasite (51). Accordingly, the prevalence of visceral Leishmaniasis (VL) is low, and recuperated patients are mainly protected against reinfection. Several genetic parameters, helminth infections, and malnutrition are associated with susceptibility to VL (63). L. donovani amastigotes initially infect the liver macrophages, namely as Kupffer cells (Figure 5). Then the leukocytes, especially neutrophils, monocytes, and $\mathrm{T}$ cells infiltrate into the liver and form granulomas that are essential in controlling the hepatic infection. The Th1 cellrelated cytokines, particularly IFN- $\gamma$ and TNF- $\alpha$, induce the ROS and reactive nitrogen intermediates (RNI) in Kupffer cells that contribute to the parasite elimination (Figure 5). L. donovani also infects the macrophages of spleen and bone marrow (51). Splenic chronic infection is associated with modification in the lymphoid compartments, apoptosis in $\mathrm{T}$ cells, and unresponsiveness to parasite antigens. The TNF- $\alpha$-deficient mice and anti-TNF- $\alpha$ antibody-treated mice did not exhibit the changes in the marginal zone macrophages after $L$. donovani infection, demonstrating the essential role that TNF- $\alpha$ plays an in the alterations of the spleen compartments (83). L. donovani also stimulates splenic regulatory DCs to secrete great amounts of IL-10 after in-vitro stimulation (84).

\section{IL-27-Linked Signals May Influence the Infection Outcome Against $L$. donovani by Direct or Indirect Suppression of the Protective Th1 Cell-Mediated Immune Responses}

The depletion of neutrophils during the initial stages of $L$. donovani infection results in the high parasite load in the bone marrow and spleen, leading to splenomegaly, delayed maturation of hepatic granulomas, and a decrease the iNOS expression within the granulomas. Along with enhanced IL-10 and IL-4 quantities (85), high IgG1/IgG2a ratio against $L$. donovani, and elevated IL-10 production by Treg cells, the susceptibility to VL is associated with the inability to induce active cell-mediated immunity against $L$. donovani (86). The IL-10 neutralization promotes IFN- $\gamma$ and TNF- $\alpha$ production and decreases the parasite load (87). L. donovani infection is not well-established in IL-10-defective mice, and the blocking of IL-10-related signaling enhances anti-parasitic immunity (87). L. donovani induces the differentiation of Th17 cells, which secrete cytokines, such as IL-17 and IL-22. The L. donovani-derived antigens stimulate PBMCs from healthy individuals to produce IL-17 and IL-22, in vitro (88). The Th1 and Th17 cells may perform complementary roles in protecting against $L$. donovani infection so that the impairment in the Th17 cell functions causes susceptibility to VL $(88,89)$. The splenic CD11c ${ }^{\text {hi }}$ MHC-II ${ }^{\text {hi }}$ DCs collected on day 21 and day 28 from $L$. donovani-infected C57BL/6 mice express high IL-27 levels (Figure 5). The L. donovani infection in BALB/c mice promotes IL-27 expression by splenic CD $8 \alpha^{+}$and $\mathrm{CD} 4^{+} \mathrm{DCs}$ on days 1,14 , and 28 post-infection (90). These results revealed that different DC subsets might be the primary IL-27 secreting cells during L. donovani infection. The circulating IL-27 quantities are elevated in $L$. donovani-infected humans, and splenic myeloid cells act as major producers of IL-27 (91). Indeed, the WSX$1^{-/-}$C57BL/6 mice show resistance to $L$. donovani infection; in addition, it effectively controls parasite load compared to wild-type mice (92). The WSX-1 ${ }^{-/}-\mathrm{C} 57 \mathrm{BL} / 6$ mice generate a potent Th1 cell-linked response that limits parasite growth; however, these $L$. donovani-infected mice display severe hepatic inflammation that eventually resolves. IL-27-linked signals may indirectly or directly suppress the protective Th1 cell-mediated immune responses against $L$. donovani infection (Figure 5).

\section{IL-27 Deficiency Correlates With Robust Th1 Cell Response After L. donovani Infection}

It was observed that the liver and spleen from $L$. donovaniinfected WSX-1 $1^{-/}$C57BL/6 mice show lower parasite loads compared with the wild-type mice on days 15 and 30 after infection (92). By day 60 after infection, both WSX-1 $1^{+/+}$ and WSX $-1^{-/}$mice efficiently control $L$. donovani loads in their liver and spleen. However, parasite loads in the liver are significantly lower in WSX-1-/- mice (92). Therefore, IL-27 is dispensable for the development of immunity against $L$. donovani but delays the resolution of the parasite infection. Apart from this, the $L$. donovani-infected WSX-1-/- mice display higher serum levels of IFN- $\gamma$ and TNF- $\alpha$ on day 15 post-infection, more elevated serum IL-12 levels on day 30 post-infection compared with WSX-1 ${ }^{+/+}$mice (92). Levels of IL-12, TNF- $\alpha$, and IFN$\gamma$ decline in $L$. donovani-infected WSX-1-/- mice by day 60 . Nonetheless, the $L$. donovani-infected WSX-1 ${ }^{+/+}$mice produce more IL-10 at all examined time points when compared with WSX-1 ${ }^{-/}$mice, but differences were not significant (92). The Leishmania antigen-stimulated spleen cells from $L$. donovaniinfected WSX-1-/- mice produce more amounts of IFN- $\gamma$ and IL-12 on day 30 post-infection and generate greater levels of NO on days 15 and 30 after infection in comparison to WSX $-1^{+/+}$mice. The splenocytes from WSX-1 $1^{-/-}$mice also produce more IL-10, indicating that IL-10 may be involved in the limiting of splenic but not hepatic inflammation in WSX$1^{-/-}$mice following $L$. donovani infection (92). IL-4 is not produced by $L$. donovani antigen-stimulated spleen cells from both mouse strains at all-time points examined (92). These findings demonstrate that WSX-1 $-/-$ mice establish a strong Th1 cell response after L. donovani infection.

\section{IL-27 Plays a Critical Role in Suppressing Hepatic Inflammation but Does Not Impart Protection Against L. donovani Infection}

Contrary to L. major infection, IL-27-related signaling is not required for the induction of the protective Th1 cell responses during $L$. donovani infection. There are some differences between $L$. donovani and $L$. major regarding the clinical, pathological, and immunological aspects. L. major infection in 
humans usually causes self-resolving cutaneous lesions, whereas L. donovani infection is related to systemic manifestations of parasite spreading in organs such as the liver, spleen, and bone marrow (63) (Figure 5). Although Th1 polarization is key to the protection from $L$. major infection, the protection against L. donovani-mediated visceral Leishmaniasis is associated with mixed Th1- and Th2-type cytokine responses; as a result, the cured VL patients display a mixed Th response (93). Although IL-4 is a vulnerability factor in mouse L. major infection, it is necessary for efficient vaccine-induced protection against $L$. donovani infection (93). WSX-1 $1^{-/}$mice display severe liver pathology after $L$. donovani infection. WSX-1-/- mice exhibit severe liver pathology with large granulomas associated with diffuse foci of inflammation and necrosis, as well as more deposition of collagen and reticulin fiber on days 15 and 30 after infection compared with wild-type mice (92). Therefore, IL-27 plays a critical role in suppressing hepatic inflammation during the acute phase of VL. As mentioned, L. donovani-infected WSX$1^{-/-}$mice produce greater levels of IL-12, IFN- $\gamma$, and TNF$\alpha$ during the early phase of infection in comparison to wildtype mice. The depletion of $\mathrm{CD}^{+} \mathrm{T}$ cells or neutralization of both TNF- $\alpha$ and IFN- $\gamma$ also reduces the severity of liver pathology in WSX-1-/- mice but renders them susceptible to L. donovani (92). Hence, the IL-27-mediated pathways suppress the tissue inflammation associated with VL by modulating the $\mathrm{CD}^{+}{ }^{+}$T-cell function (Figure 5). However, blockade of IFN- $\gamma$ or TNF- $\alpha$ alone is not sufficient to block liver inflammation or compromise host resistance in WSX-1-/- mice (92). Therefore, IFN- $\gamma$ or TNF- $\alpha$ production alone may not be adequate to induce immunopathology in the liver. These findings demonstrate that the IL-27-related pathways, in contrast to its protective role in $L$. major infection, are involved in the pathogenesis of $L$. donovani infection.

\section{Immunomodulatory Effects of IL-27 During L. Donovani Infection}

It has been indicated that the IL- $10^{+} \mathrm{IL}-27^{+}$DCs can promote IL10 production by Th1 cells in vivo (94). In L. donovani infected C57BL/6 mice, the frequency of splenic IFN- $\gamma^{+}$IL- $10^{+}$T-bet $^{+}$ $\mathrm{CD}^{+}{ }^{+} \mathrm{T}$ cells is increased on day 28 post-infection (94). IL27 directly alters methylation patterns in $\mathrm{CD}^{+} \mathrm{T}$ cells at the IL-10 gene promoter, thus causing higher IL-10 expression (95) (Figure 5). IL-27 supports IL-10 production by IFN- $\gamma$-producing Th1 cells through STAT1, STAT4, and Notch signaling molecules via an alternate pathway $(96,97)$. The optimal generation of CD ${ }^{+} \mathrm{IL}-10^{+} \mathrm{T}$ cells by IL-27 requires c-Maf, ICOS, and IL-21 expression $(98,99)$. Further, IL-27 and IL-21 together enhance the expansion and differentiation of IL-10-secreting $\operatorname{Tr} 1$ cells during VL (40, 51). IL-21 also reinforces the IL-10 secretion by IL-27-induced Tr1 cells (100). Therefore, IL-27 controls the severity of VL-associated inflammation by inducing antiinflammatory cytokine IL-10. Recently, in a mouse model of L. donovani infection using $\mathrm{BALB} / \mathrm{c}$ mice, it has been reported that the administration of the neutralizing anti-EBI3 antibody (but not anti-p28 antibody) to pathogen-infected mice reduce the parasite load in the spleen and liver, and increase the TNF$\alpha$ - and IFN- $\gamma$-secreting cells (101). As EBI3 is shared by IL-35 and IL-27, it has been concluded that IL-35 may have more immunomodulatory effects during $L$. donovani infection (101). These regulatory effects of IL-27 during L. donovani infection are summarized in Figure 5.

Collectively, IL-27 is expressed by different DC subsets during the early phase of L. donovani infection, IL-27 may directly and/or indirectly suppress the protective Th1 cell-mediated responses against $L$. donovani infection, which may delay the resolution of the parasite infection. The $L$. donovani-infected WSX-1 $1^{-/}$mice exhibit a diversion in Th1/Th2 cells toward Th1 cell responses. During L. donovani infection, $\mathrm{CD}^{+}{ }^{+} \mathrm{T}$ cells play a critical role in mediating hepatic damage in WSX-1-/mice wherein IL-27 attenuates immune-pathological responserelated tissue damages by inducing the expression of the antiinflammatory cytokine IL-10 by Tr1- and Th1 cells.

\section{Role of IL-27 in L. infantum Infection}

L. infantum infection in humans and animal models leads to an increase in the IL-27 expression (102). High levels of the p28 subunit of IL-27 are detected in the spleen and liver of L. infantum-infected C57BL/6 mice at 4 and 6 weeks postinfection. The expression of both IL-27R subunits, including WSX-1 and gp130, are upregulated mainly in the fourth week after infection, indicating that the expression of IL-27 and its receptor is induced during $L$. infantum infection (103). The in-vitro experiments indicated that the bone-marrow-derived macrophages (BMDMs) and BMDCs from C57BL/6 mice can produce IL-27 when infected with L. infantum (103). The Leishmania-derived nucleic acids (DNA and RNA) are recognized by intracellular TLRs like TLR3, TLR7, TLR8, and TLR9 $(63,104)$. The BMDMs are deficient in TLR3 and TLR9 or adaptor molecules MyD88 and TRIF are not able to produce IL-27 after L. infantum infection, indicating that nucleic acids from $L$. infantum activate these pathways to trigger the IL-27 production. L. infantum infection induces IL-27 production in a consecutive process that includes the events, engagement of TLR3 and TLR9, the IFN- $\beta$ induction, and activation of IRF1 that lead to IL-27 production in macrophages infected with $L$. infantum. The soluble CD40L also increases the production of several cytokines (IL-12p70, IL-23, IL-27, IL-15, and IL-1 $\beta$ ) by $L$. infantum-infected human macrophages in vitro (105). A negative correlation was observed between the levels of these cytokines in the supernatants of cultured macrophages with the number of infected macrophages as well as amastigotes. Leishmania may also trigger sCD14 and initiate the IL-27, IL-10, and IL-6 production, which subsequently modulate macrophage microbicidal activity, facilitating Leishmania proliferation (106).

\section{IL-27 Is a Regulatory Cytokine That Dictates Susceptibility to $L$. infantum Infection}

For experimental VL both $\mathrm{C} 57 \mathrm{BL} / 6$ and $\mathrm{BALB} / \mathrm{c}$ strains are considered as susceptible models, but only $\mathrm{BALB} / \mathrm{c}$ mice, not C57BL/6 mice displayed the augmented serum IL-27 levels during an early stage of $L$. infantum infection. The phenomenon was attributed to the upregulation of p28 expression by splenic DCs and higher parasite burdens in BALB/c mice 


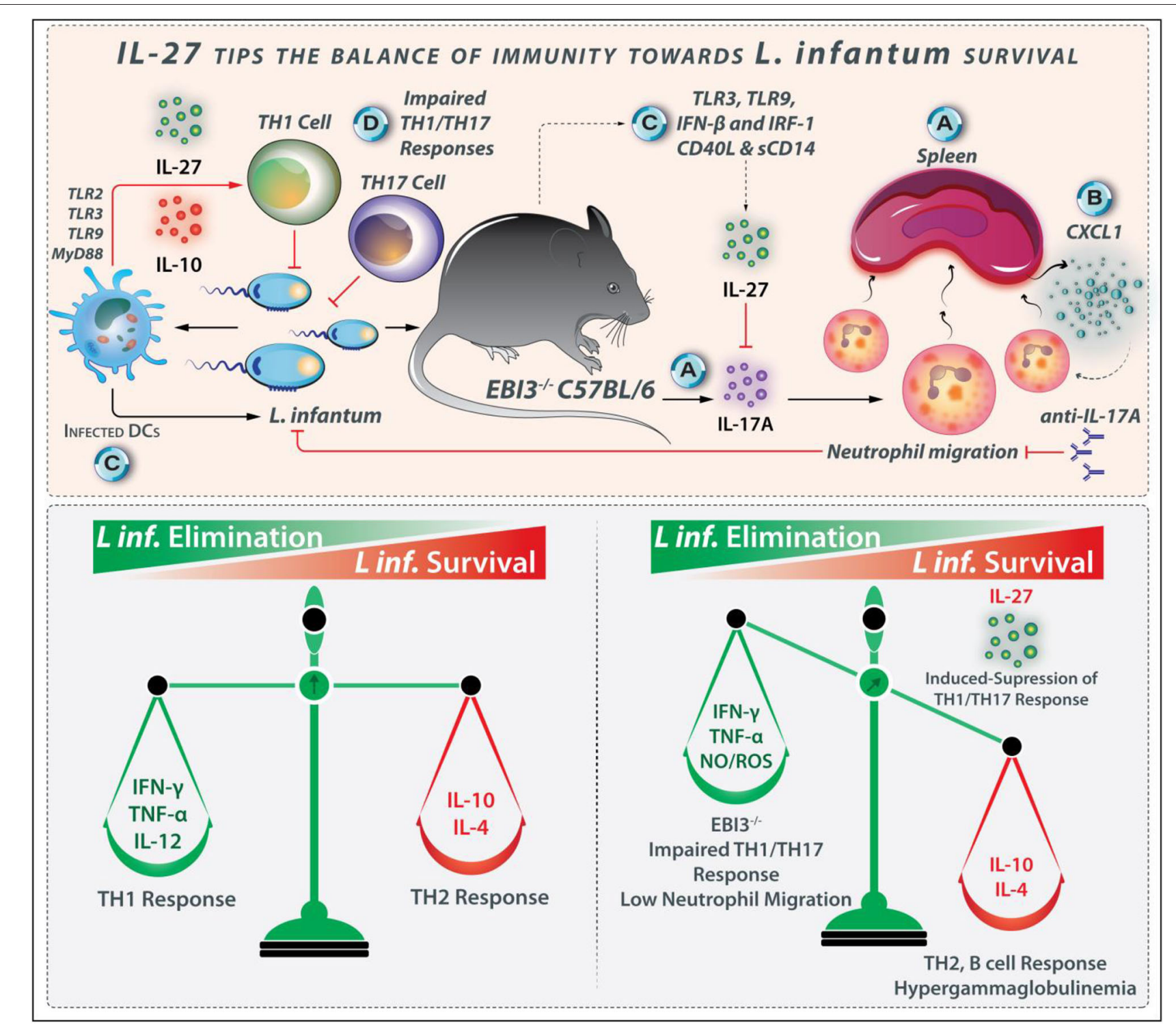

FIGURE 6 | IL-27 tips the balance of immunity toward $L$. infantum survival. IL-27 plays a role in the suppression of the protective immune response during $L$. infantum infection. (A) In $\mathrm{EBI}^{-/-}$mice, IL-27 modulates the IL-17 production and neutrophil infiltration. (B) Higher expression of powerful neutrophil chemoattractant CXCL1 is observed in the spleen of $\mathrm{EBI}^{-1-}$ mice. (C) IL-27 and its receptor expressed during the early phase of $L$. infantum infection where infected DCs and macrophages are the major producers of this cytokine in pathways originating from TLR3, TLR9, and IFN- $\beta$. (D) As Th1 and Th17 cells-related responses help combat $L$. infantum infection, IL-27 is regarded as the susceptibility factor because of its ability to interfere with Th1- and Th17-induced protection.

(102). High expression of TLR2 by DCs from BALB/c mice may support the early IL-27 expression after infection, which contributes to the attenuating of inflammation and promoting infection (102). It has been reported that the L. infantuminfected BMDCs from BALB/c mice produce higher IL27 levels than C57BL/6 mice. Whereas, the LPS-stimulated BMDCs from C57BL/6 mice produce higher amounts of IL27 than BALB/c mice (102), indicating that parasite vigorously upregulates the secretion of IL-27 in BMDCs derived from $\mathrm{BALB} / \mathrm{c}$, but not from C57BL/6 mice. In both cutaneous and visceral forms of human Leishmaniasis, the IL-27 production is increased when the disease is in the active phase (91, 106). When compared with healthy subjects and delayed-type hypersensitivity (DTH) positive individuals, the sera from VL patients before treatment showed high levels of cytokinesIFN- $\gamma$, IL-10, IL-6, IL-27, and TNF- $\alpha$. Besides, the serum levels of these cytokines decrease after treatment (106). B cell activation is also promoted by IL-27, exacerbating the hypergammaglobulinemia in VL patients (106). In a mouse model of VL, IL-27 plays a role in the suppression of the protective immune response during $L$. infantum infection, which can lead to disease exacerbation (103). IL-27 suppresses 
the immune response in VL through the induction of IL10 production in vivo (91). The IL-27 restricts the Th1 cell polarization via inducing the IL-10-producing DCs. In fact, in the $\mathrm{p} 28^{-/-}$mouse model restricted to DCs, CD4 ${ }^{+} \mathrm{T}$ cellrelated IFN- $\gamma$ response is exacerbated (107). The collective production of both IL-27 and IL-10 by L. donovani-infected DCs is essential for IL-10 production by Th1 cells, resulting in parasite persistence (94).

\section{IL-27 Modulates IL-17 to Affect Neutrophil Infiltration in the Spleen of $L$. infantum Infected Mice}

The administration of rIL-27 to in C57BL/6 increases the IL10 production, while decreasing IFN- $\gamma$ and IL-12p70 in the peritoneal cavity, and prevents the infiltration of neutrophils in the spleen $24 \mathrm{~h}$ after the treatment (102). IL-27 neutralization in acutely infected $\mathrm{BALB} / \mathrm{c}$ mice reduces parasite burdens and reduces IL-10 levels, while leads to a transient increase in the splenic IFN- $\gamma$-producing $\mathrm{CD}^{+}$and $\mathrm{CD}^{+}{ }^{+} \mathrm{T}$ cells $(102)$. The investigations using $\mathrm{EBI}^{-/-}$mice indicate a role for IL-27 in modulating the IL-17 production and neutrophil infiltration during the chronic phase of $L$. infantum infection $(102,103)$. The $\mathrm{EBI}^{-/-}$mice produce considerably higher IL-17A levels than wild-type C57BL/6 mice in both spleen and liver. Restimulation of $\mathrm{EBI}^{-/-}$mice-derived splenocyte with $L$. infantum lysate leads to significant IL-17A production. IL-17A is the critical mediator of neutrophil infiltration in the spleen of infected mice (Figure 6), which induces chemoattractant-CXCL1 expression (103). Higher CXCL1 expression is observed in the spleen of $\mathrm{EBI}^{-/-}$mice, which causes elevated neutrophil migration at the fourth week post-infection in the spleen and liver.

\section{IL-27 Leads to Host Vulnerability to L. infantum by Reducing the Neutrophil Influx}

Neutrophils have diverse mechanisms for combating pathogens, some of which include the production of cytokines and chemokines that lead to inflammatory cell recruitment as well as the release of proteolytic-enzymes/cathepsin/neutrophilelastase and neutrophil extracellular traps (NETs) mediatedpathogen killing $(108,109)$. Host resistance through neutrophils in response to Leishmania depends on both the host's genetic background as well as the invading Leishmania species (63). For example, L. amazonensis promastigotes are eliminated by NETs, while L. major may survive within neutrophils (110). The host's genetic factors also affect neutrophil performance during Leishmaniasis. The neutrophil-defective C57BL/6 mice display a common L. major infection, while neutrophil-defective $\mathrm{BALB} / \mathrm{c}$ mice exhibit a weak harmful Th2 cell response (111). The neutrophil-defective Genista mice are resistant to L. mexicana that causes non-healing lesions. During VL, neutrophils play a protective role. In C57BL/6 mice during L. infantum infection, IL-17A levels are reduced in the infected organs (103). The downregulation of IL-17A is mediated by IL-27, as EBI3 deficiency leads to intensified IL-17A secretion. Upon IL-17A neutralization, the resistant $\mathrm{EBI} 3^{-/-}$mice become as susceptible as the control wild-type mice, representing the ability of IL-27 to prevent the IL-17A production directly. Moreover, neutrophil infiltration is also reduced after anti-IL-17A treatment, satisfying the role of IL-17A in neutrophil recruitment to infected organs in parallel to the induction of NO production by macrophages (103). The inhibition of IL-17A by IL-27 during L. infantum infection leads to host vulnerability by reducing the neutrophil influx. Although the EBI3-deficiency impairs the Th1 responses in L. infantum-infected mice, other arms of the inflammatory response such as IL-17A and neutrophils limit the parasite load even in the absence of efficient Th1 cell response (103). Based on the discussion above, the regulatory effects of IL-27 during $L$. infantum infection are shown in Figure 6.

IL-27 and its receptor are expressed on the infected macrophages and DCs during the early phase of L. infantum infection. TLR3- and TLR9-, and IFN- $\beta$ related signaling pathways play a prominent role in IL-27 production during $L$. infantum infection (Figure 6). In addition to the mouse strains, other molecules such as soluble CD40L and sCD14 also influence IL-27 production (112). In L. infantum-infected humans with VL, the IL-27 levels are increased in the active phase, and coming back to basal amounts after treatment, represent that this cytokine may be considered as a marker of VL severity or prognosis. IL27 is a regulatory cytokine that plays a role in susceptibility to L. infantum infection. As Th1- and Th17 cell-related responses confer protection against L. infantum infection (113), IL-27 increases the susceptibility to parasite by interfering with both protective Th1 and Th17 responses.

\section{Role of IL-27 in L. amazonensis Infection}

The C57BL/6 mice are vulnerable to $L$. mexicana or $L$. amazonensis infection due to compromised Th1 cell responses (114). This inability has been attributed to elevated IL-10 production, which causes insufficient DC activation and IL-12 production. Although Th1 cell-mediated immunity limits the Leishmania infection, the Th1 cell-released cytokines like TNF- $\alpha$ and IFN- $\gamma$ involve in the immunopathologic reactions. Indeed, elevated TNF- $\alpha$ and IFN- $\gamma$ quantities were detected in severe $\mathrm{CL}$ and ML patients. L. amazonensis causes anergic DCL and CL with disseminated lesions (50). A different modulating role has been proposed for Treg cells in L. amazonensis infection. The Treg transfers from Leishmania-infected mice to naive mice shortly before L. amazonensis infection decreases lesion development signifying that the role of Treg, cells in limiting immunopathological responses (115). The results from an invitro analyses indicate that the expression of both IL-27 subunits, including p28 and EBI3, is augmented in L. amazonensis-infected macrophages from $\mathrm{C} 57 \mathrm{BL} / 6$ mice measured at 4 hours after infection (116).

\section{IL-27 Is a Susceptibility Factor During $L$. amazonensis Infection}

In L. amazonensis-infected C57BL/6 mice, the injection of the rIL-27 into the infected footpads (on days 2, 4, and 6 prior infections) strongly enhances the lesion sizes and parasite number in the footpads and the draining lymph nodes at weeks 2 and 3 following infection (116). Although IL-27 signaling contributes to the Th1 cell-related protective response in the $L$. major-infected mice, the same pathway may enhance the susceptibility to L. amazonensis, perhaps 


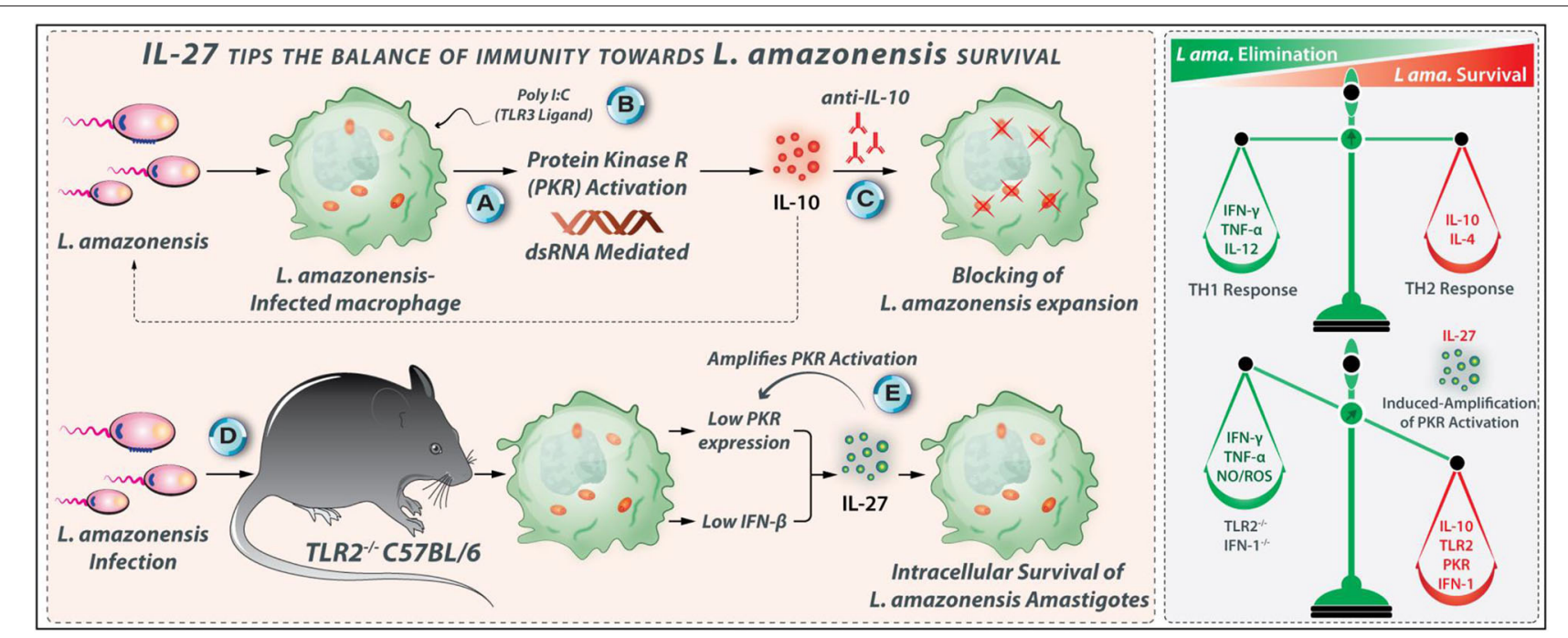

FIGURE 7 | IL-27 tips the balance of immunity toward L. amazonensis survival. IL-27-related enhancing effects on $L$. amazonensis growth and survival occur mainly through IL-10. (A) Inside macrophages, L. amazonensis activates protein kinase R (PKR). (B) PKR activation can also occur through Poly I:C (a ligand for TLR3), which elicits IL-10 production. (C) Using anti-IL-10 antibody parasite replication could be entirely abrogated. (D) TLR2-/- macrophages express low levels of IFN- $\beta$ and PKR post-L. amazonensis infection, indicating that the TLR2-PKR-IFN-1 axis contributes to the IL-27 production during L. amazonensis infection that supports parasite survival. (E) Interestingly, when produced, IL-27 triggers more PKR activation, which triggers its production by a positive feedback mechanism.

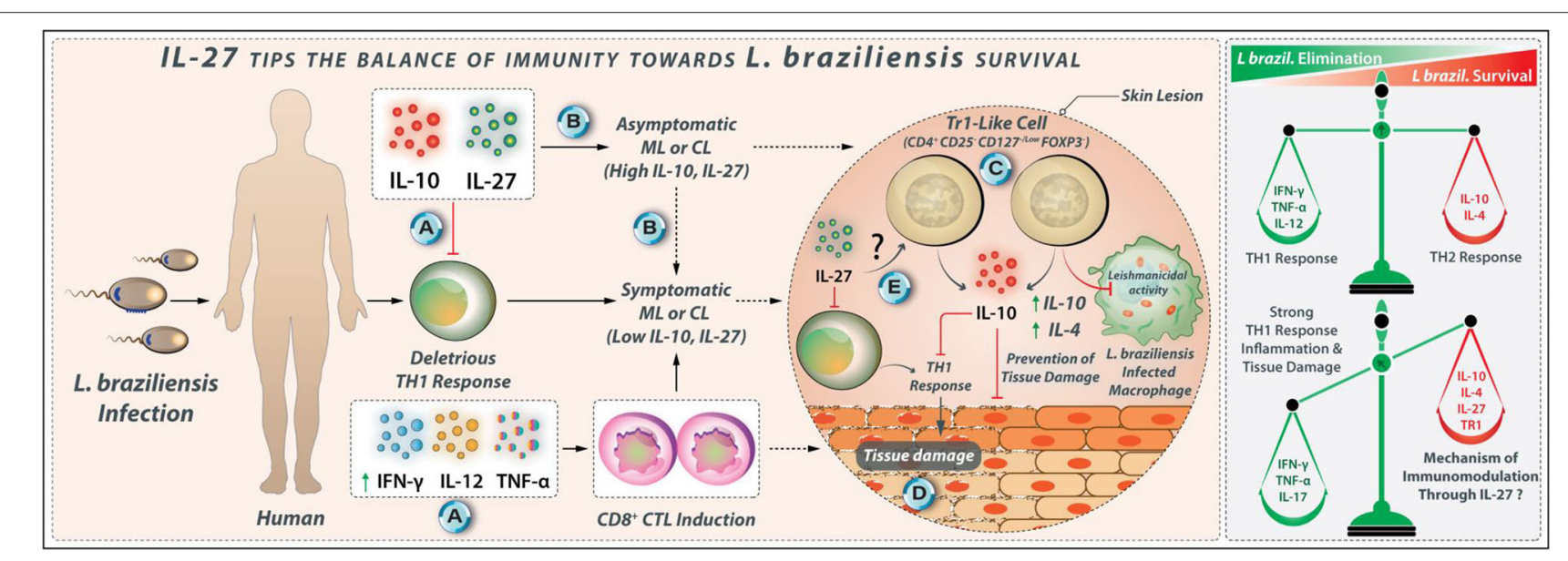

FIGURE 8 | IL-27 tips the balance of immunity toward L. braziliensis survival. (A) IL-10 and IL-27 may modulate deleterious Th1 responses in L. braziliensis infection. (B) The proper expression of IL-10 and IL-27 may cause asymptomatic subclinical pattern, while the reduced expression of IL-10 and IL-27 may lead to symptomatic $C L$ pattern in $L$. braziliensis infected individuals. (C) Tr1 cells with phenotype CD4 ${ }^{+} C D 25^{-}$CD127-/low FoxP3- are identified in the peripheral blood of $L$. braziliensis-infected patients with CL that produce higher amounts of IL-10. (D) Tr1 cells at the initial phase of infection may suppress the Leishmanicidal mechanisms of macrophages. However, during the late stages of infection, IL-27, along with IL-10, attenuates tissue damage in L. braziliensis infection. (E) The mechanism through which $\operatorname{Tr} 1$ cells are induced by IL-27 is unknown to date.

due to the differences in protein kinase $\mathrm{R}$ (PKR)-mediated signaling between $L$. major- and L. amazonensis-infected macrophages. The PKR-mediated signaling supports $L$. amazonensis but reduces L. major infection (117). L. amazonensis activates PKR in macrophages for their survival. The PKR activation by poly I:C (a ligand for TLR3) causes IL-10 production, and IL-10 neutralization prevents the parasite expansion (118), suggesting a TLR3-PKR-IL-27-IL-10 axis in $L$. amazonensis infection.
TLR2-PKR-IFN-1 Signaling Contributes to $L$. amazonensis Survival in an IL-27 Dependent Manner

It is reported that the addition of rIL-27 to human macrophages infected with $L$. amazonensis promastigotes augments the parasite propagation and percentage of infected cells measured on days 3 and 4 after the cytokine addition. The IL-27 neutralization or IL-10 receptor blockade in the infected cell cultures markedly reduce the parasite multiplication (116). Hence, the IL-27-related enhancing effects on L. amazonensis 
survival and growth occur mainly through IL-10. Treatment of the L. amazonensis-infected human macrophages with a PKR inhibitor abrogates the IL-27-mediated L. amazonensis replication. PKR is activated by IL-27, which is crucial to IL-27mediated Leishmania expansion (116). TLR2-deficient C57BL/6 mice are also less susceptible to $L$. amazonensis infection than wild-type counterparts (63). TLR $2^{-/-}$macrophages express low quantities of IFN- $\beta$ and PKR post-L. amazonensis infection (63). Indeed, L. amazonensis infection leads to the activation of the PKR/IFN-1 axis via a TLR2-dependent manner, which promotes parasite replication in macrophages (116). Interestingly, the Leishmania-induced IL-27 expression also depends on the TLR2 and IFN-1-mediated signaling (119). The expression of IL-27 is profoundly diminished in infected-macrophages derived from TLR $2^{-/-}$or IFN-1R $\mathrm{R}^{-/-}$mice $(116,119)$. TLR2-PKR-IFN-1 signaling contributes to the IL-27 production in L. amazonensisinfected macrophages that lead to the intracellular survival of the parasite. When produced, IL-27 elicits new cycles of PKR activation, which supports parasite expansion (116). These regulatory effects of IL-27 during L. amazonensis infection are depicted in Figure 7.

The L. amazonensis-infected macrophages may be one of the main sources of IL-27 during the infection. IL-27 profoundly increases the vulnerability $L$. amazonensis infection, and its promoting effects on the parasite survival and growth occur mainly through an IL-10-dependent manner. Indeed, the TLR2PKR-IFN-1 axis contributes to the IL-27 production during $L$. amazonensis infection that supports the survival of the parasite. When produced, IL-27 triggers more PKR activation, which stimulates its production by a positive feedback mechanism. Accordingly, the targeting of TLR2, PKR, and IFN-1 may impair the IL-27 production, which eventually diminishes the $L$. amazonensis replication.

\section{Role of IL-27 in L. braziliensis Infection}

The L. braziliensis-related CL is associated with robust Th1 responses $(65,120)$ conferring protection against the parasite. However, excessive uncontrolled inflammation is responsible for the development of skin lesions and tissue damages, as observed in ML and CL patients (118). Reduced IL-10 production along with the heightened IFN- $\gamma$ and TNF- $\alpha$ production are positively correlated with lesions sizes and tissue damage in CL and ML $(118,121)$. A high number of cytotoxic cells are also observed in lesions of patients with CL caused by L. braziliensis and correlated with explicit inflammatory stress and cutaneous tissue damage (122). Patients treated with anti-inflammatory drugs show alleviated lesions size, supporting the deleterious role of inflammation during the L. braziliensis infection (65). The PBMCs from L. braziliensis-infected individuals with CL pattern produce higher levels of IFN- $\gamma$ and TNF- $\alpha$ than cells from patients with subclinical (SC) pattern after in-vitro stimulation with SLA (123). The SLA-stimulated PBMCs from patients with SC tend to express higher amounts of IL-17 compared with patients with CL pattern (124). The addition of rIL-27 to SLA-stimulated PBMCs from patients with CL reduces IFN- $\gamma$ production $(81,124)$. Further, higher IL-10 levels were detected in L. braziliensis-infected individuals with SC pattern when compared with CL patients (125). Therefore, IL-10 and IL-27 may modulate the deleterious Th1 cell responses in L. braziliensis infection. Hence, the proper expression of the IL-10 and IL-27 may cause an asymptomatic SC form, while the low expression of IL-10 and IL-27 may lead to symptomatic CL pattern in braziliensis-infected individuals (Figure 8).

\section{IL-27 in L. braziliensis Infection}

IL-10 and TGF- $\beta$, but not IL-27, modulate the expression of the TNF- $\alpha$, IFN- $\gamma$, and IL-17 by SLA-stimulated PBMCs from ML and CL patients (118). IL-27 was unable to enhance IL10 production by PBMCs from CL and ML patients (81). The PBMCs from CL and ML patients are unresponsive to the immunomodulatory effects of IL-27. In skin biopsy from patients with $L$. braziliensis-related CL, the increased IL-10 and IL-27 expression were also associated with high IFN- $\gamma$ expression, although a similar pattern of cytokine expression was not observed in ML group (126). A positive association has been indicated between the IL-10 expression and IL-27, IL21 , and IFN- $\gamma$ expression but not with the FOXP3 expression in lesions of patients with CL (127). A new subgroup of Treg cells, namely Tr1-like cells with $\mathrm{CD} 4^{+} \mathrm{CD} 25^{-} \mathrm{CD} 127^{-/ \text {low }}$ FOXP3 $^{-}$phenotype was identified in the peripheral blood of L. braziliensis-infected patients with $\mathrm{CL}$ that produce higher levels of IL-10 (127). The secretion of IL-10 from $\mathrm{CD}^{+}$ $\mathrm{CD}^{-} 5^{-} \mathrm{FOXP}^{-}$cells in the initial phase may suppress the Leishmanicidal mechanisms of macrophages, which supports the establishment of infection (127). However, in chronic stages, when a strong Th1 response is dominant, Tr1-like cells may help in protecting tissues from damage caused by an inflammatory reaction. The possible IL-27 contribution to the development of the Tr1-like cells needs to be further investigated. The regulatory effects of IL-27 during L. braziliensis infection are shown in Figure 8.

Collectively, the excessive uncontrolled Th1 cell-mediated inflammation is involved in the tissue damages in ML and CL L. braziliensis. The IL-27, in parallel with IL-10, attenuates the deleterious Th1 cell response during the late stage of the $L$. braziliensis infection (124). However, the precise role of the IL-27 during the early stage of L. braziliensis infection needs more clarification.

\section{CONCLUSION}

IL-27 is expressed during the early phase of Leishmania infection, and the infected phagocytes and DCs are the major producers of this cytokine. The role of IL-27 in Leishmania infection is species-dependent (Table 1). The protective role of IL-27 during the initial stage of $L$. major infection is exerted mainly through inhibition of IL-4-mediated Th2 cell responses. Therefore, evaluation of the local therapeutic potential of IL-27 or its agonists concerning the L. major-mediated $\mathrm{CL}$ requires more investigations. In mouse models of OVAinduced asthma, the intranasal IL-27 administration significantly improves the clinical symptoms of the disease, decreases the local eosinophilia in the nasal mucosa, modulates the cytokine production by Th1, Th2, and Treg cells, and decrease the 
TABLE 1 | Experimental studies indicating the role of IL-27 in Leishmaniasis disease.

\begin{tabular}{|c|c|c|c|c|c|}
\hline $\begin{array}{l}\text { Parasite } \\
\text { species }\end{array}$ & Mouse strain & $\begin{array}{l}\text { Infective } \\
\text { dose* }^{*}\end{array}$ & $\begin{array}{l}\text { Infection } \\
\text { site }\end{array}$ & Observation & References \\
\hline L. major & WT C57BL/6 & $1 \times 10^{3} \mathrm{MP}$ & Ear dermis & $\begin{array}{l}\text { - P28 expression is increased in infected tissue at week two post-infection. } \\
\text { - EBI3 expression becomes detectable in infected tissue at week five post-infection. }\end{array}$ & (68) \\
\hline L. major & $\begin{array}{l}\text { WSX-1-1- } \\
\text { C57BL/6 }\end{array}$ & $1 \times 10^{3} \mathrm{MP}$ & Ear dermis & $\begin{array}{l}\text { - The mice exhibit more severe lesions that were associated with the appearance of the } \\
\mathrm{IL}-17^{+} \mathrm{CD} 4^{+} \text {cells. } \\
\text { - } \mathrm{IL}-27 \text { administration prevents the development of abnormal Th17 cells during } \\
\text { Leishmaniasis. } \\
\text { - The mice display a low percentage of } \mathrm{IL}-10^{+} \mathrm{IFN}-\gamma^{-} \mathrm{CD} 4^{+} \text {cells and more severe } \\
\text { lesions at week } 6 \text { post-infection. }\end{array}$ & (68) \\
\hline L. major & WT C57BL/6 & $2 \times 10^{5} \mathrm{MP}$ & Ear dermis & - CD11 $\mathrm{C}^{+}$DCs express P28 and EBI3 in draining lymph nodes at $24 \mathrm{~h}$ post-infection. & (69) \\
\hline L. major & $\mathrm{EB} \mid 3^{-/-} \mathrm{C} 57 \mathrm{BL} / 6$ & $2 \times 10^{5} \mathrm{MP}$ & Ear dermis & $\begin{array}{l}\text { - Mice display greater susceptibility to infections with maximum parasites loads and } \\
\text { lesion sizes at week six post-infection. } \\
\text { - At weeks } 2 \text { and } 4 \text { post-infection, the IFN- } \gamma \text { secretion is lower, while the IL-4, IL-10, and } \\
\text { IL-13 secretion were higher by L. major lysate-stimulated lymphocytes. } \\
\text { - At early time points after infection, the Th1/Th2 balance is diverted toward Th2 cells. } \\
\text { - Protective immunologic memory is not impaired in EBI3-/- mice. } \\
\text { - IL-27 is essential for early control of parasite replication. }\end{array}$ & (69) \\
\hline L. major & $\begin{array}{l}\text { WSX-1-/- } \\
\text { C57BL/6 }\end{array}$ & $2 \times 10^{6} \mathrm{MP}$ & Hind footpad & 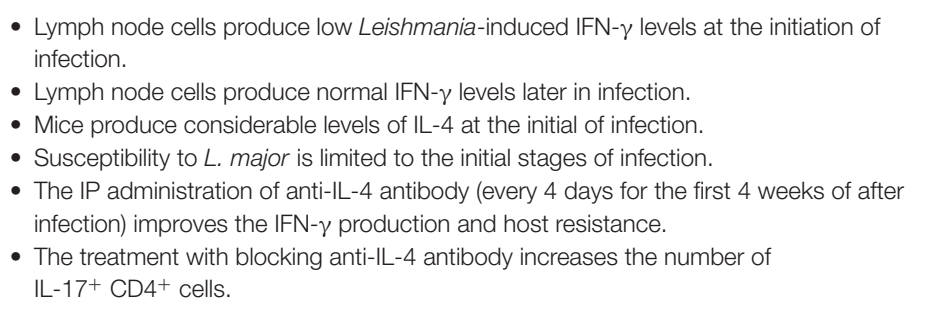 & (71) \\
\hline L. major & WT BALB/c & $2 \times 10^{5} \mathrm{PM}$ & $\begin{array}{l}{ }^{\dagger} \text { S.C into the } \\
\text { hind footpad }\end{array}$ & $\begin{array}{l}\text { - Administration of IL-27 reduces the parasite load. } \\
\text { - Administration of IL-27 increases the survival rate. } \\
\text { - Lymph node cells from IL-27-treated mice secrete higher IFN- } \gamma \text { quantities and lower } \\
\text { IL-4 levels. }\end{array}$ & (34) \\
\hline L. donovani & WT C57BL/6 & $3 \times 10^{7} \mathrm{AM}$ & Intravenously & $\begin{array}{l}\text { - Splenic } \mathrm{CD} 11 \mathrm{C}^{\text {hi }} \mathrm{MHCI} \mathrm{h}^{\mathrm{hi}} \mathrm{CDC} \text { s collected at days } 21 \text { and } 28 \text { post-infection express high } \\
\text { IL-27 levels. } \\
\text { - The DC-derived IL-27 may enhance the IFN- } \gamma^{+} \mathrm{IL}-10^{+} \mathrm{CD} 4^{+} \text {cell polarization in vivo. }\end{array}$ & (94) \\
\hline L. donovani & WT BALB/c & $2 \times 10^{7-8} A M$ & Intravenously & $\begin{array}{l}\text { - Infection promotes the IL-27 expression by splenic CD } 8 \alpha^{+} \text {and CD4+ DC at days } 1,14 \text {, } \\
\text { and } 28 \text { post-infection. }\end{array}$ & (90) \\
\hline L. donovani & $\begin{array}{l}\text { WSX-1-/- } \\
\text { C57BL/6 }\end{array}$ & $1 \times 10^{7} \mathrm{AM}$ & Intravenously & $\begin{array}{l}\text { - Mice contain fewer parasites in livers on days } 15,30 \text {, and } 60 \text { after infection. } \\
\text { - Mice show high resistance to } L \text {. donovani infection. } \\
\text { - Mice display higher serum IFN- } \gamma \text { and TNF- } \alpha \text { level on day } 15 \text { post-infection. } \\
\text { - Mice display higher serum IL-12 levels on day } 30 \text { post-infection. } \\
\text { - By day } 60 \text {, levels of IL-12, TNF- } \alpha \text {, and IFN- } \gamma \text { drop in mice. } \\
\text { - The Leishmania antigen-stimulated spleen cells produce more amounts of IFN- } \gamma \text { and } \\
\text { IL-12 on day } 30 \text { post-infection and produce more significant levels of NO on days } 15 \\
\text { and } 30 \text { after infection. } \\
\text { - Mice mount a robust Th1 cell response after } L \text {. donovani infection. } \\
\text { - Mice display severe liver pathology. } \\
\text { - The depletion of CD4 } 4^{+} \text {T cells reduces liver pathology. } \\
\text { - Neutralization of both TNF- } \alpha \text { and IFN- } \gamma \text { reduces liver pathology. }\end{array}$ & (92) \\
\hline L. donovani & WT BALB/c & $2.5 \times 10^{7} \mathrm{AM}$ & Intravenously & $\begin{array}{l}\text { - Administration of the neutralizing anti-EBI3 antibody (and not anti-p28 antibody) to } \\
\text { pathogen-infected mice reduces the parasite load in the spleen and liver and increase } \\
\text { the TNF- } \alpha \text { - and IFN- } \gamma \text {-secreting cells. }\end{array}$ & (101) \\
\hline L. infantum & $\begin{array}{l}\text { WT C57BL/6 } \\
\text { WT BALB/c }\end{array}$ & $1 \times 10^{8} \mathrm{PM}$ & Intravenously & $\begin{array}{l}\text { - Serum IL-27 levels are increased early (at } 4 \text { days after infection) in the BALB/c mice, but } \\
\text { not in C57BL/6 mice. } \\
\text { - The splenic DCs from BALB/c mice but not from C57BL/6 mice upregulate the } \\
\text { expression of IL-27p28 } 24 \mathrm{~h} \text { after infection. } \\
\text { - IL-27 secretion by BMDCs from BALB/c was higher compared to C57BL/6, whereas } \\
\text { the LPS-stimulated BMDCs from C57BL/6 mice produce more elevated amounts of } \\
\text { IL-27 than BALB/c mice. } \\
\text { - The administration of rIL-27 to in C57BL/6 increase the production of IL-10, while } \\
\text { decrease IFN- } \gamma \text { and IL-12p70, and prevent the infiltration of neutrophils in the spleen at } \\
24 \mathrm{~h} \text { after treatment in comparison with infected non-treated animals. }\end{array}$ & (102) \\
\hline
\end{tabular}


TABLE 1 | Continued

\begin{tabular}{|c|c|c|c|c|}
\hline $\begin{array}{l}\text { Parasite } \\
\text { species }\end{array}$ & Mouse strain & $\begin{array}{l}\text { Infective } \\
\text { dose* }\end{array}$ & $\begin{array}{l}\text { Infection } \\
\text { site }\end{array}$ & Observation \\
\hline & & & & $\begin{array}{l}\text { - Neutralization of IL-27 in acutely infected BALB/c decreases parasite burdens } \\
\text { transiently reduces IL-10 and a transient increase in splenic IFN- } \gamma \text { producing } \mathrm{CD}^{+}{ }^{+} \text {and } \\
\mathrm{CD} 8^{+} \mathrm{T} \text { cells. }\end{array}$ \\
\hline L. infantum & WT C57BL/6 & $1 \times 10^{7} \mathrm{PM}$ & Intravenously & $\begin{array}{l}\text { - High levels of the P28 subunit of IL-27 are detected in the spleen and liver at weeks } 4 \\
\text { and } 6 \text { post-infection. } \\
\text { - The expression of both IL-27R subunits, including WSX-1 and gp130, are upregulated } \\
\text { at week } 4 \text { after infection. }\end{array}$ \\
\hline L. infantum & $\mathrm{EBI3}^{-/-} \mathrm{C} 57 \mathrm{BL} / 6$ & $1 \times 10^{7} \mathrm{PM}$ & Intravenously & $\begin{array}{l}\text { - The parasite loads in the liver and spleen were lower at weeks } 4 \text { and } 6 \text { post-infection. } \\
\text { - Mice produce higher IL-17A levels in both spleen and liver. } \\
\text { - Restimulation splenocyte with L. infantum lysate leads to more IL-17A production. } \\
\text { - Higher CXCL1expression was observed in the spleen, which causes a peak in } \\
\text { neutrophil migration at week } 4 \text { post-infection in the spleen and liver. } \\
\text { - When IL-17 was blocked, the mice become as susceptible as the C57BL/6 control. }\end{array}$ \\
\hline $\begin{array}{l}\text { L. } \\
\text { amazonensis }\end{array}$ & WT C57BL/6 & $5 \times 10^{5} \mathrm{PM}$ & Hind footpad & $\begin{array}{l}\text { - The IL-27 administration into the infected footpads (on days 2, 4, and } 6 \text { after infection) } \\
\text { enhances the lesion sizes and parasite number in the footpads and the draining lymph } \\
\text { nodes in weeks } 2 \text { and } 3 \text { following infection. }\end{array}$ \\
\hline
\end{tabular}

References

Neutralization of IL-27 in acutely infected BALB/c decreases parasite burdens transiently reduces $\mathrm{IL}-10$ and a transient increase in splenic IFN- $\gamma$ producing $\mathrm{CD}^{+}{ }^{+}$and

and 6 post-infection. nodes in weeks 2 and 3 following infection.

${ }^{\star}$ AM, Amastigotes; MP, Metacyclic promastigotes; PM, Promastigotes; ${ }^{\dagger}$ SC, Subcutaneous.

serum levels of specific $\operatorname{IgE}(128,129)$. The effects of such intranasal IL-27 administration need to be investigated in various Leishmania sp. infections.

Leishmania skews naive T cells toward Th2 cells for its survival in the host. On the other hand, IL-27 has the capability to polarize naïve $\mathrm{T}$ cells to Th1 cells, which plays host protective roles by jeopardizing parasite growth in the host. Nonetheless, IL-27 may suppress the protective immune responses against L. donovani, L. infantum, L. amazonensis, and L. braziliensis. Therefore, T cell-dependent IL-27 functions are diverse, speciesspecific, and contradictory. At the same time, the infection and pathology of the Leishmania species are unique and vary with IL-27 dependency. The targeting of IL-27 or its receptor using blocking monoclonal antibodies, small molecule inhibitors, and siRNA, alone or in combination with other therapeutic agents, needs to be evaluated as promising strategies for the treatment of the L. donovani-, L. infantum-, L. amazonensis-, and L. braziliensis-related complications. IL-27 or IL-27 associated signaling molecules may be considered as exciting novel targets for immunomodulation in Leishmaniasis. Further, the clinical values of IL-27 as a marker of Leishmaniasis severity and/or as a monitoring marker of treatment efficacy need more considerations. It may be underlined that IL-27 possesses the

\section{REFERENCES}

1. Jones GW, Hill DG, Cardus A, Jones SA. IL-27: a double agent in the IL-6 family. Clin Exp Immunol. (2018) 193:37-46. doi: 10.1111/cei. 13116

2. Wang Q, Liu J. Regulation and immune function of IL-27. In: Ma X, editor. Regulation of Cytokine Gene Expression in Immunity and Diseases. Dordrecht: Springer (2016). p. 191-211.

3. Abdalla AE, Li Q, Xie L, Xie J. Biology of IL-27 and its role in the host immunity against mycobacterium tuberculosis. Int J Biol Sci. (2015) 11:16875. doi: $10.7150 /$ ijbs. 10464 potential to be a valuable biomarker for active human VL and for monitoring the effectiveness of treatment modality.

\section{AUTHOR CONTRIBUTIONS}

AJ, MN, and IS conceptualized and drafted the manuscript and Table 1. BS and AS scrutinized the scientific-content, language, grammar, and edited the manuscript. AP and PC contributed additionally to writing and reviewed the manuscript. PC conceptualized, designed, and digitalized the figures. All authors contributed to the article and approved the submitted version.

\section{FUNDING}

BS's work was supported by the JC Bose Fellowship and IndoIran Bilateral Exchange Program, the Department of Science and Technology, Government of India.

\section{ACKNOWLEDGMENTS}

The authors would like to thank Prof. Tamas Laskay and Arathi Nair for their critical evaluation and valuable suggestions regarding figures and the manuscript.
4. Molle C, Nguyen M, Flamand V, Renneson J, Trottein F, De Wit D, et al. IL27 synthesis induced by TLR ligation critically depends on IFN regulatory factor 3. J Immunol. (2007) 178:7607-15. doi: 10.4049/jimmunol.178. 12.7607

5. Blahoianu MA, Rahimi AA, Kozlowski M, Angel JB, Kumar A. IFN- $\gamma$-induced IL-27 and IL-27p28 expression are differentially regulated through JNK MAPK and PI3K pathways independent of Jak/STAT in human monocytic cells. Immunobiology. (2014) 219:1-8. doi: 10.1016/j.imbio.2013.06.001

6. Pirhonen J, Siren J, Julkunen I, Matikainen S. IFN- $\alpha$ regulates Toll-like receptor-mediated IL-27 gene expression in human 
macrophages. J Leukocyte Biol. (2007) 82:1185-92. doi: 10.1189/jlb.03 07157

7. Molle C, Goldman M, Goriely S. Critical role of the IFN-stimulated gene factor 3 complex in TLR-mediated IL-27p28 gene expression revealing a two-step activation process. J Immunol. (2010) 184:1784-92. doi: 10.4049/jimmunol.0902005

8. Zhang J, Qian X, Ning H, Eickhoff CS, Hoft DF, Liu J. Transcriptional suppression of IL-27 production by Mycobacterium tuberculosis-activated p38 MAPK via inhibition of AP-1 binding. J Immunol. (2011) 186:5885-95. doi: 10.4049/jimmunol.1003447

9. Kim HS, Go H, Akira S, Chung DH. TLR2-mediated production of IL27 and chemokines by respiratory epithelial cells promotes bleomycininduced pulmonary fibrosis in mice. J Immunol. (2011) 187:4007-17. doi: 10.4049/jimmunol.1101654

10. Jankowski M, Kopinski P, Goc A. Interleukin-27: biological properties and clinical application. Archivum Immunol Therap Exp. (2010) 58:417-25. doi: 10.1007/s00005-010-0098-6

11. Wirtz S, Becker C, Fantini MC, Nieuwenhuis EE, Tubbe I, Galle PR, et al. EBV-induced gene 3 transcription is induced by TLR signaling in primary dendritic cells via NF- $\mathrm{\kappa B}$ activation. J Immunol. (2005) 174:2814-24. doi: 10.4049/jimmunol.174.5.2814

12. Yoshida H, Hunter CA. The immunobiology of interleukin-27. Ann Rev Immunol. (2015) 33:417-43. doi: 10.1146/annurev-immunol-032414-112134

13. Garbers C, Spudy B, Aparicio-Siegmund S, Waetzig GH, Sommer J, Hölscher C, et al. An interleukin-6 receptor-dependent molecular switch mediates signal transduction of the IL-27 cytokine subunit p28 (IL-30) via a gp130 protein receptor homodimer. J Biol Chem. (2013) 288:4346-54. doi: $10.1074 /$ jbc.M112.432955

14. Hall A, Silver J, Hunter C. The immunobiology of IL-27. Adv Immunol. (2012) 115:1-44. doi: 10.1016/B978-0-12-394299-9.00001-1

15. Hunter CA, Kastelein R. Interleukin-27: balancing protective and pathological immunity. Immunity. (2012) 37:960-9. doi: 10.1016/j.immuni.2012.11.003

16. Owaki T, Asakawa M, Morishima N, Mizoguchi I, Fukai F, Takeda $\mathrm{K}$, et al. STAT3 is indispensable to IL-27-mediated cell proliferation but not to IL-27-induced Th1 differentiation and suppression of proinflammatory cytokine production. J Immunol. (2008) 180:2903-11. doi: 10.4049/jimmunol.180.5.2903

17. Rottenberg ME, Carow B. SOCS3, a major regulator of infection and inflammation. Front Immunol. (2014) 5:58. doi: 10.3389/fimmu.2014.00058

18. Fabbi M, Carbotti G, Ferrini S. Dual roles of IL-27 in cancer biology and immunotherapy. Mediators Inflamm. (2017) 2017:3958069. doi: 10.1155/2017/3958069

19. Konjević GM, Vuletić AM, Martinović KMM, Larsen AK, Jurišić VB. The role of cytokines in the regulation of NK cells in the tumor environment. Cytokine. (2019) 117:30-40. doi: 10.1016/j.cyto.2019.02.001

20. Hunter CA. New IL-12-family members: IL-23 and IL-27, cytokines with divergent functions. Nat Rev Immunol. (2005) 5:521-31. doi: $10.1038 /$ nri1648

21. Li J, Wu H, Xing W, Yang S, Lu S, Du W, et al. Interleukin-27 as a negative regulator of human neutrophil function. Scand J Immunol. (2010) 72:284-92. doi: 10.1111/j.1365-3083.2010.02422.x

22. Petes C, Wynick C, Guzzo C, Mehta D, Logan S, Banfield BW, et al. IL-27 enhances LPS-induced IL-1 $\beta$ in human monocytes and murine macrophages. J Leukocyte Biol. (2017) 102:83-94. doi: 10.1189/jlb.3A0316-098R

23. Carbotti G, Barisione G, Airoldi I, Mezzanzanica D, Bagnoli M, Ferrero S, et al. IL-27 induces the expression of IDO and PD-L1 in human cancer cells. Oncotarget. (2015) 6:43267-80. doi: 10.18632/oncotarget.6530

24. Wang S, Miyazaki Y, Shinozaki Y, Yoshida H. Augmentation of antigen-presenting and Th1-promoting functions of dendritic cells by WSX-1 (IL-27R) deficiency. J Immunol. (2007) 179:6421-28. doi: 10.4049/jimmunol.179.10.6421

25. Li M-S, Liu Z, Liu J-Q, Zhu X, Liu Z, Bai X-F. The Yin and Yang aspects of IL-27 in induction of cancer-specific T-cell responses and immunotherapy. Immunotherapy. (2015) 7:191-200. doi: 10.2217/imt.14.95

26. Murugaiyan G, Saha B. IL-27 in tumor immunity and immunotherapy. Trends Mol Med. (2013) 19:108-16. doi: 10.1016/j.molmed.2012.12.002
27. Karakhanova S, Bedke T, Enk AH, Mahnke K. IL-27 renders DC immunosuppressive by induction of B7-H1. J Leukocyte Biol. (2011) 89:83745. doi: $10.1189 / \mathrm{jlb} .1209788$

28. Morandi F, Di Carlo E, Ferrone S, Petretto A, Pistoia V, Airoldi I. IL27 in human secondary lymphoid organs attracts myeloid dendritic cells and impairs HLA class I-restricted antigen presentation. J Immunol. (2014) 192:2634-42. doi: 10.4049/jimmunol.1302656

29. Mchedlidze T, Kindermann M, Neves A, Voehringer D, Neurath M, Wirtz S. IL-27 suppresses type 2 immune responses in vivo via direct effects on group 2 innate lymphoid cells. Mucosal Immunol. (2016) 9:1384-94. doi: $10.1038 / \mathrm{mi} .2016 .20$

30. Villarino AV, Larkin J, Saris CJ, Caton AJ, Lucas ST, de Sauvage FJ, et al. Positive and negative regulation of the IL-27 receptor during lymphoid cell activation. J Immunol. (2005) 174:7684-91. doi: 10.4049/jimmunol.174.12.7684

31. Takeda A, Hamano S, Yamanaka A, Hanada T, Ishibashi T, Mak TW, et al. Cutting edge: role of IL-27/WSX-1 signaling for induction of T-bet through activation of STAT1 during initial Th1 commitment. J Immunol. (2003) 170:4886-90. doi: 10.4049/jimmunol.170.10.4886

32. Owaki T, Asakawa M, Kamiya S, Takeda K, Fukai F, Mizuguchi J, et al. IL-27 suppresses CD28-medicated IL-2 production through suppressor of cytokine signaling 3. J Immunol. (2006) 176:2773-80. doi: 10.4049/jimmunol.176.5.2773

33. Murugaiyan G, Mittal A, Lopez-Diego R, Maier LM, Anderson DE, Weiner HL. IL-27 is a key regulator of IL-10 and IL-17 production by human CD4+ T cells. J Immunol. (2009) 183:2435-43. doi: 10.4049/jimmunol.0900568

34. Yoshimoto T, Yoshimoto T, Yasuda K, Mizuguchi J, Nakanishi K. IL-27 suppresses Th2 cell development and Th2 cytokines production from polarized Th2 cells: a novel therapeutic way for Th2-mediated allergic inflammation. J Immunol. (2007) 179:4415-23. doi: 10.4049/jimmunol.179.7.4415

35. Harrington LE, Hatton RD, Mangan PR, Turner H, Murphy TL, Murphy $\mathrm{KM}$, et al. Interleukin 17-producing CD4+ effector T cells develop via a lineage distinct from the Thelper type 1 and 2 lineages. Nat Immunol. (2005) 6:1123-32. doi: 10.1038/ni1254

36. Diveu C, McGeachy MJ, Boniface K, Stumhofer JS, Sathe M, Joyce-Shaikh B, et al. IL-27 blocks RORc expression to inhibit lineage commitment of Th17 cells. J Immunol. (2009) 182:5748-56. doi: 10.4049/jimmunol.0801162

37. Hirahara K, Ghoreschi K, Yang X-P, Takahashi H, Laurence A, Vahedi $\mathrm{G}$, et al. Interleukin-27 priming of T cells controls IL-17 production in trans via induction of the ligand PD-L1. Immunity. (2012) 36:1017-30. doi: 10.1016/j.immuni.2012.03.024

38. Jafarzadeh A, Larussa T, Nemati M, Jalapour S. T cell subsets play an important role in the determination of the clinical outcome of helicobacter pylori infection. Microb Pathog. (2018) 116:227-36. doi: 10.1016/j.micpath.2018.01.040

39. Rodríguez-Perea A, Arcia E, Rueda C, Velilla P. Phenotypical characterization of regulatory $\mathrm{T}$ cells in humans and rodents. Clin Exp Immunol. (2016) 185:281-91. doi: 10.1111/cei.12804

40. Chihara N, Madi A, Karwacz K, Awasthi A, Kuchroo VK. Differentiation and characterization of Tr1 cells. Curr Protocol Immunol. (2016) 113:3.27.13.27.10. doi: 10.1002/0471142735.im0327s113

41. Hall AOH, Beiting DP, Tato C, John B, Oldenhove G, Lombana CG, et al. The cytokines interleukin 27 and interferon- $\gamma$ promote distinct Treg cell populations required to limit infection-induced pathology. Immunity. (2012) 37:511-23. doi: 10.1016/j.immuni.2012.06.014

42. Angkasekwinai P. Th9 cells in allergic disease. Curr Allergy Asthma Rep. (2019) 19:29. doi: 10.1007/s11882-019-0860-8

43. Murugaiyan G, Beynon V, Da Cunha AP, Joller N, Weiner HL. IFN- $\gamma$ limits Th9-mediated autoimmune inflammation through dendritic cell modulation of IL-27. J Immunol. (2012) 189:5277-83. doi: 10.4049/jimmunol. 1200808

44. Crotty S. T Follicular helper cell biology: a decade of discovery and diseases. Immunity. (2019) 50:1132-48. doi: 10.1016/j.immuni.2019.04.011

45. Batten M, Ramamoorthi N, Kljavin NM, Ma CS, Cox JH, Dengler HS, et al. IL-27 supports germinal center function by enhancing IL-21 production and the function of T follicular helper cells. J Exp Med. (2010) 207:2895-906. doi: $10.1084 /$ jem. 20100064 
46. Boumendjel A, Tawk LR, de Waal M, Boulay V, Yssel H, Pène J. IL-27 induces the production of IgG1 by human B cells. Eur Cytokine Netw. (2006) 17:281-9.

47. Mittal A, Murugaiyan G, Beynon V, Hu D, Weiner HL. IL-27 induction of IL21 from human CD8+ T cells induces granzyme B in an autocrine manner. Immunol Cell Biol. (2012) 90:831-5. doi: 10.1038/icb.2012.14

48. Alvar J, Vélez ID, Bern C, Herrero M, Desjeux P, Cano J, et al. Leishmaniasis worldwide and global estimates of its incidence. PLoS ONE. (2012) 7:e35671. doi: 10.1371/journal.pone.0035671

49. Torres-Guerrero E, Quintanilla-Cedillo MR, Ruiz-Esmenjaud J, Arenas R. Leishmaniasis: a review. F1000Research. (2017) 6:750. doi: 10.12688/f1000research.11120.1

50. Khosravi A, Sharifi I, Fekri A, Kermanizadeh A, Bamorovat M, Mostafavi M, et al. Clinical features of anthroponotic cutaneous leishmaniasis in a major focus, Southeastern Iran, 1994-2014. Iran J Parasitol. (2017) 12:544-53.

51. Faleiro RJ, Kumar R, Hafner LM, Engwerda CR. Immune regulation during chronic visceral leishmaniasis. PLoS Negl Trop Dis. (2014) 8:e2914. doi: 10.1371/journal.pntd.0002914

52. Maspi N, Abdoli A, Ghaffarifar F. Pro-and anti-inflammatory cytokines in cutaneous leishmaniasis: a review. Pathog Glob Health. (2016) 110:247-60. doi: 10.1080/20477724.2016.1232042

53. Titus RG, Ribeiro J. Salivary gland lysates from the sand fly Lutzomyia longipalpis enhance Leishmania infectivity. Science. (1988) 239:1306-8. doi: $10.1126 /$ science. 3344436

54. Gomes R, Oliveira F. The immune response to sand fly salivary proteins and its influence on Leishmania immunity. Front Immunol. (2012) 3:110. doi: 10.3389/fimmu.2012.00110

55. Gomes R, Teixeira C, Teixeira MJ, Oliveira F, Menezes MJ, Silva C, et al. Immunity to a salivary protein of a sand fly vector protects against the fatal outcome of visceral Leishmaniasis in a hamster model. Proc Natl Acad Sci. (2008) 105:7845-50. doi: 10.1073/pnas.0712153105

56. Collin N, Gomes R, Teixeira C, Cheng L, Laughinghouse A, Ward JM, et al. Sand fly salivary proteins induce strong cellular immunity in a natural reservoir of visceral Leishmaniasis with adverse consequences for Leishmania. PLoS Pathog. (2009) 5:e1000441. doi: 10.1371/journal.ppat.1000441

57. Lestinova T, Rohousova I, Sima M, de Oliveira CI, Volf P. Insights into the sand fly saliva: blood-feeding and immune interactions between sand flies, hosts, and Leishmania. PLoS Negl Trop Dis. (2017) 11:e0005600. doi: 10.1371/journal.pntd.0005600

58. Schnurr M, Toy T, Shin A, Wagner M, Cebon J, Maraskovsky E. Extracellular nucleotide signalling via P2 receptors inhibits IL-12 and enhances IL-23 expression in human dendritic cells: a novel role for the cAMP pathway. Blood. (2005) 105:1582-9. doi: 10.1182/blood-2004-05-1718

59. Goncalves R, Zhang X, Cohen H, Debrabant A, Mosser DM. Platelet activation attracts a subpopulation of effector monocytes to sites of Leishmania major infection. J Exp Med. (2011) 208:1253-65. doi: 10.1084/jem.20101751

60. Costa DJ, Favali C, Clarêncio J, Afonso L, Conceiçao V, Miranda JC, et al. Lutzomyia longipalpis salivary gland homogenate impairs cytokine production and costimulatory molecule expression on human monocytes and dendritic cells. Infect Immun. (2004) 72:1298-305. doi: 10.1128/IAI.72.3.1298-1305.2004

61. Valenzuela JG, Garfield M, Rowton ED, Pham VM. Identification of the most abundant secreted proteins from the salivary glands of the sand fly Lutzomyia longipalpis, vector of Leishmania chagasi. J Exp Biol. (2004) 207:3717-29. doi: 10.1242/jeb.01185

62. Soares MB, Titus RG, Shoemaker CB, David JR, Bozza M. The vasoactive peptide maxadilan from sand fly saliva inhibits TNF- $\alpha$ and induces IL-6 by mouse macrophages through interaction with the pituitary adenylate cyclase-activating polypeptide (PACAP) receptor. J Immunol. (1998) 160:1811-6.

63. Jafarzadeh A, Nemati M, Sharifi I, Nair A, Shukla D, Chauhan P, et al. Leishmania species-dependent functional duality of toll-like receptor 2 . IUBMB Life. (2019) 71:1685-700. doi: 10.1002/iub.2129

64. Kostka SL, Dinges S, Griewank K, Iwakura Y, Udey MC, Von Stebut E. IL17 promotes progression of cutaneous leishmaniasis in susceptible mice. $J$ Immunol. (2009) 182:3039-46. doi: 10.4049/jimmunol.0713598
65. Scott P, Novais FO. Cutaneous leishmaniasis: immune responses in protection and pathogenesis. Nat Rev Immunol. (2016) 16:581-92. doi: $10.1038 /$ nri.2016.72

66. Olekhnovitch R, Ryffel B, Müller AJ, Bousso P. Collective nitric oxide production provides tissue-wide immunity during Leishmania infection. J Clin Investig. (2014) 124:1711-22. doi: 10.1172/JCI72058

67. Wei X-Q, Charles IG, Smith A, Ure J, Feng G-J, Huang F-P, et al. Altered immune responses in mice lacking inducible nitric oxide synthase. Nature. (1995) 375:408-11. doi: 10.1038/375408a0

68. Anderson CF, Stumhofer JS, Hunter CA, Sacks D. IL-27 regulates IL-10 and IL-17 from CD4+ cells in nonhealing Leishmania major infection. J Immunol. (2009) 183:4619-27. doi: 10.4049/jimmunol.0804024

69. Zahn S, Wirtz S, Birkenbach M, Blumberg RS, Neurath MF, von Stebut E. Impaired Th1 responses in mice deficient in Epstein-Barr virus-induced gene 3 and challenged with physiological doses of Leishmania major. Eur J Immunol. (2005) 35:1106-12. doi: 10.1002/eji.200425926

70. Yoshida H, Hamano S, Senaldi G, Covey T, Faggioni R, Mu S, et al. WSX1 is required for the initiation of Th1 responses and resistance to L. major infection. Immunity. (2001) 15:569-78. doi: 10.1016/S1074-7613(01)00206-0

71. Artis D, Johnson LM, Joyce K, Saris C, Villarino A, Hunter CA, et al. Cutting edge: early IL-4 production governs the requirement for IL-27WSX-1 signaling in the development of protective Th1 cytokine responses following Leishmania major infection. J Immunol. (2004) 172:4672-5. doi: 10.4049/jimmunol.172.8.4672

72. Tolouei S, Ghaedi K, Khamesipour A, Akbari M, Baghaei M, Hasheminia S, et al. IL-23 and IL-27 levels in macrophages collected from peripheral blood of patients with healing vs non-healing form of cutaneous leishmaniasis. Iran J Parasitol. (2012) 7:18-25.

73. Martinez GJ, Nurieva RI, Yang XO, Dong C. Regulation and function of proinflammatory TH17 cells. Ann NY Acad Sci. (2008) 1143:188. doi: 10.1196/annals.1443.021

74. Cobb D, Smeltz RB. Regulation of proinflammatory Th17 responses during Trypanosoma cruzi infection by IL-12 family cytokines. J Immunol. (2012) 188:3766-73. doi: 10.4049/jimmunol.1103478

75. Pflanz S, Timans JC, Cheung J, Rosales R, Kanzler H, Gilbert J, et al. IL-27, a heterodimeric cytokine composed of EBI3 and p28 protein, induces proliferation of naive CD4+ T cells. Immunity. (2002) 16:779-90. doi: 10.1016/S1074-7613(02)00324-2

76. Hibbert L, Pflanz S, de Waal Malefyt R, Kastelein RA. IL-27 and IFN$\alpha$ signal via Stat 1 and Stat 3 and induce T-Bet and IL-12R $\beta 2$ in naive T cells. J Interferon Cytokine Res. (2003) 23:513-22. doi: 10.1089/107999003607 08632

77. Belkaid Y, Mendez S, Lira R, Kadambi N, Milon G, Sacks D. A natural model of Leishmania major infection reveals a prolonged "silent" phase of parasite amplification in the skin before the onset of lesion formation and immunity. J Immunol. (2000) 165:969-77. doi: 10.4049/jimmunol.165.2.969

78. Hamano S, Himeno K, Miyazaki Y, Ishii K, Yamanaka A, Takeda A, et al. WSX-1 is required for resistance to Trypanosoma cruzi infection by regulation of proinflammatory cytokine production. Immunity. (2003) 19:657-67. doi: 10.1016/S1074-7613(03)00298-X

79. Miyazaki $Y$, Inoue $H$, Matsumura $M$, Matsumoto $K$, Nakano T, Tsuda $\mathrm{M}$, et al. Exacerbation of experimental allergic asthma by augmented Th2 responses in WSX-1-deficient mice. J Immunol. (2005) 175:2401-7. doi: 10.4049/jimmunol.175.4.2401

80. Lucas S, Ghilardi N, Li J, de Sauvage JF. IL-27 regulates IL-12 responsiveness of naive $\mathrm{CD} 4+\mathrm{T}$ cells through Stat1-dependent andindependent mechanisms. Proc Natl Acad Sci. (2003) 100:15047-52. doi: $10.1073 /$ pnas. 2536517100

81. Oliveira WN, Ribeiro LE, Schrieffer A, Machado P, Carvalho EM, Bacellar O. The role of inflammatory and anti-inflammatory cytokines in the pathogenesis of human tegumentary leishmaniasis. Cytokine. (2014) 66:12732. doi: 10.1016/j.cyto.2013.12.016

82. Chatelain R, Varkila K, Coffman RL. IL-4 induces a Th2 response in Leishmania major-infected mice. J Immunol. (1992) 148:1182-7.

83. Engwerda CR, Ato M, Cotterell SE, Mynott TL, Tschannerl A, GorakStolinska PM, et al. A role for tumor necrosis factor- $\alpha$ in remodeling the splenic marginal zone during Leishmania donovani infection. Am J Pathol. (2002) 161:429-37. doi: 10.1016/S0002-9440(10)64199-5 
84. Wakkach A, Fournier N, Brun V, Breittmayer J-P, Cottrez F, Groux $\mathrm{H}$. Characterization of dendritic cells that induce tolerance and $\mathrm{T}$ regulatory 1 cell differentiation in vivo. Immunity. (2003) 18:605-17. doi: 10.1016/S1074-7613(03)00113-4

85. McElrath M, Murray H, Cohn Z. The dynamics of granuloma formation in experimental visceral leishmaniasis. J Exp Med. (1988) 167:1927-37. doi: 10.1084/jem.167.6.1927

86. Bhattacharya P, Ghosh S, Ejazi SA, Rahaman M, Pandey K, Das VNR, et al. Induction of IL-10 and TGF $\beta$ from CD4+ CD25+ FoxP3+ T cells correlates with parasite load in Indian kala-azar patients infected with Leishmania donovani. PLoS Negl Trop Dis. (2016) 10:e0004422. doi: 10.1371/journal.pntd.0004422

87. Gautam S, Kumar R, Maurya R, Nylén S, Ansari N, Rai M, et al. IL10 neutralization promotes parasite clearance in splenic aspirate cells from patients with visceral leishmaniasis. J Infect Dis. (2011) 204:1134-7. doi: 10.1093/infdis/jir461

88. Pitta MG, Romano A, Cabantous S, Henri S, Hammad A, Kouriba B, et al. IL-17 and IL-22 are associated with protection against human kala azar caused by Leishmania donovani. J Clin Investig. (2009) 119:2379-87. doi: 10.1172/JCI38813

89. Zijlstra EE. The immunology of post-kala-azar dermal leishmaniasis (PKDL). Parasit Vect. (2016) 9:464. doi: 10.1186/s13071-016-1721-0

90. Maroof A, Kaye PM. Temporal regulation of interleukin-12p70 (IL12p70) and IL-12-related cytokines in splenic dendritic cell subsets during Leishmania donovani infection. Infect Immun. (2008) 76:239-49. doi: 10.1128/IAI.00643-07

91. Ansari NA, Kumar R, Gautam S, Nylén S, Singh OP, Sundar S, et al. IL-27 and IL-21 are associated with T cell IL-10 responses in human visceral leishmaniasis. J Immunol. (2011) 186:3977-85. doi: 10.4049/jimmunol.1003588

92. Rosas LE, Satoskar AA, Roth KM, Keiser TL, Barbi J, Hunter C, et al. Interleukin-27R (WSX-1/T-cell cytokine receptor) gene-deficient mice display enhanced resistance to Leishmania donovani infection but develop severe liver immunopathology. Am J Pathol. (2006) 168:158-69. doi: 10.2353/ajpath.2006.050013

93. Basu R, Bhaumik S, Basu JM, Naskar K, De T, Roy S. Kinetoplastid membrane protein-11 DNA vaccination induces complete protection against both pentavalent antimonial-sensitive and-resistant strains of Leishmania donovani that correlates with inducible nitric oxide synthase activity and IL-4 generation: evidence for mixed Th1-and Th2-like responses in visceral leishmaniasis. J Immunol. (2005) 174:7160-71. doi: 10.4049/jimmunol.174.11.7160

94. Owens BM, Beattie L, Moore JW, Brown N, Mann JL, Dalton JE, et al. IL10-producing Th1 cells and disease progression are regulated by distinct CD11c+ cell populations during visceral leishmaniasis. PLoS Pathog. (2012) 8:e1002827. doi: 10.1371/journal.ppat.1002827

95. Hedrich CM, Ramakrishnan A, Dabitao D, Wang F, Ranatunga D, Bream JH. Dynamic DNA methylation patterns across the mouse and human IL10 genes during CD4+ T cell activation; influence of IL-27. Mol Immunol. (2010) 48:73-81. doi: 10.1016/j.molimm.2010.09.009

96. Batten M, Kljavin NM, Li J, Walter MJ, de Sauvage FJ, Ghilardi N. Cutting edge: IL-27 is a potent inducer of IL-10 but not FoxP3 in murine T cells. $J$ Immunol. (2008) 180:2752-6. doi: 10.4049/jimmunol.180.5.2752

97. Rutz S, Janke M, Kassner N, Hohnstein T, Krueger M, Scheffold A. Notch regulates IL-10 production by T helper 1 cells. Proc Natl Acad Sci USA. (2008) 105:3497-502. doi: 10.1073/pnas.0712102105

98. Apetoh L, Quintana FJ, Pot C, Joller N, Xiao S, Kumar D, et al. The aryl hydrocarbon receptor interacts with c-Maf to promote the differentiation of type 1 regulatory T cells induced by IL-27. Nat Immunol. (2010) 11:854. doi: $10.1038 /$ ni. 1912

99. Pot C, Jin H, Awasthi A, Liu SM, Lai C-Y, Madan R, et al. Cutting edge: IL-27 induces the transcription factor c-Maf, cytokine IL-21, and the costimulatory receptor ICOS that coordinately act together to promote differentiation of IL-10-producing Tr1 cells. J Immunol. (2009) 183:797-801. doi: 10.4049/jimmunol.0901233

100. Spolski R, Kim H-P, Zhu W, Levy DE, Leonard WJ. IL-21 mediates suppressive effects via its induction of IL-10. J Immunol. (2009) 182:2859-67. doi: 10.4049/jimmunol.0802978
101. Asad M, Sabur A, Shadab M, DIDWANIA N, ALI N. EB1-3 chain of IL-35 along with TGF- $\beta$ synergistically regulate anti-leishmanial immunity. Front Immunol. (2019) 10:616. doi: 10.3389/fimmu.2019.02409

102. Pérez-Cabezas B, Cecílio P, Robalo AL, Silvestre R, Carrillo E, Moreno J, et al. Interleukin-27 early impacts Leishmania infantum infection in mice and correlates with active visceral disease in humans. Front immunol. (2016) 7:478. doi: 10.3389/fimmu.2016.00478

103. Quirino GF, Nascimento MS, Davoli-Ferreira M, Sacramento LA, Lima MH, Almeida RP, et al. Interleukin-27 (IL-27) mediates susceptibility to visceral Leishmaniasis by suppressing the IL-17-neutrophil response. Infect Immun. (2016) 84:2289-98. doi: 10.1128/IAI.00283-16

104. de Freitas EO, de Leoratti FMS, Freire-de-Lima CG, Morrot A, Feijó DF. The contribution of immune evasive mechanisms to parasite persistence in visceral leishmaniasis. Front Immunol. (2016) 7:153. doi: 10.3389/fimmu.2016.00153

105. de Oliveira Barreto FA, Bomfim AS, Leite LGS, dos Santos TRS, dos Santos PL, de Almeida RP, et al. Soluble CD40 ligand in sera of subjects exposed to Leishmania infantum infection reduces the parasite load in macrophages. PLoS ONE. (2015) 10:e0141265. doi: 10.1371/journal.pone.0141265

106. dos Santos PL, de Oliveira FA, Santos MLB, Cunha LCS, Lino MT, de Oliveira MF, et al. The severity of visceral leishmaniasis correlates with elevated levels of serum IL-6, IL-27 and sCD14. PLoS Negl Trop Dis. (2016) 10:e0004375. doi: 10.1371/journal.pntd.0004375

107. Zhang S, Liang R, Luo W, Liu C, Wu X, Gao Y, et al. High susceptibility to liver injury in IL-27 p28 conditional knockout mice involves intrinsic interferon- $\gamma$ dysregulation of CD4+ T cells. Hepatology. (2013) 57:1620-31. doi: 10.1002/hep.26166

108. Guimarães-Costa AB, Nascimento MT, Froment GS, Soares RP, Morgado $\mathrm{FN}$, Conceição-Silva F, et al. Leishmania amazonensis promastigotes induce and are killed by neutrophil extracellular traps. Proc Natl Acad Sci. (2009) 106:6748-53. doi: 10.1073/pnas.0900226106

109. Yang F, Feng C, Zhang X, Lu J, Zhao Y. The diverse biological functions of neutrophils, beyond the defense against infections. Inflammation. (2017) 40:311-23. doi: 10.1007/s10753-016-0458-4

110. Salei N, Hellberg L, Köhl J, Laskay T. Enhanced survival of Leishmania major in neutrophil granulocytes in the presence of apoptotic cells. PLOS ONE. (2017) 12:e0171850. doi: 10.1371/journal.pone.0171850

111. Tacchini-Cottier F, Zweifel C, Belkaid Y, Mukankundiye C, Vasei M, Launois $\mathrm{P}$, et al. An immunomodulatory function for neutrophils during the induction of a CD4+ Th2 response in BALB/c mice infected with Leishmania major. J Immunol. (2000) 165:2628-36. doi: 10.4049/jimmunol.165. 5.2628

112. de Oliveira Silva FA, Damascena CVO, Passos NP, Duthie RO, Guderian MS, Bhatia JA, et al. High levels of soluble CD40 ligand and matrix metalloproteinase-9 in serum are associated with favorable clinical evolution in human visceral leishmaniasis. BMC Infect Dis. (2013) 13:331. doi: 10.1186/1471-2334-13-331

113. Gonçalves-de-Albuquerque SdC, Pessoa-e-Silva R, Trajano-Silva LA, de Goes TC, de Morais RCS, Cíntia CNdC, de Lorena VMB, et al. The equivocal role of Th17 cells and neutrophils on immunopathogenesis of leishmaniasis. Front Immunol. (2017) 8:1437. doi: 10.3389/fimmu.2017. 01437

114. Velasquez LG, Galuppo MK, De Rezende E, Brandao WN, Peron JP, Uliana $\mathrm{SR}$, et al. Distinct courses of infection with Leishmania (L.) amazonensis are observed in BALB/c, BALB/c nude and C57BL/6 mice. Parasitology. (2016) 143:692-703. doi: 10.1017/S003118201600024X

115. Ji J, Masterson J, Sun J, Soong L. CD4+ CD25+ regulatory T cells restrain pathogenic responses during Leishmania amazonensis infection. J Immunol. (2005) 174:7147-53. doi: 10.4049/jimmunol.174.11.7147

116. Barreto-de-Souza V, Ferreira PL, de Carvalho Vivarini A, Calegari-Silva T, Soares DC, Regis EG, et al. IL-27 enhances Leishmania amazonensis infection via ds-RNA dependent kinase (PKR) and IL-10 signaling. Immunobiology. (2015) 220:437-44. doi: 10.1016/j.imbio.2014.11.006

117. Pereira RM, Teixeira KLD, Barreto-de-Souza V, Calegari-Silva TC, De-Melo LD, Soares DC, et al. Novel role for the double-stranded RNA-activated protein kinase PKR: modulation of macrophage infection by the protozoan parasite Leishmania. FASEB J. (2010) 24:617-26. doi: 10.1096/fj.09-1 40053 
118. Bacellar O, Lessa H, Schriefer A, Machado P, de Jesus AR, Dutra WO, et al. Up-regulation of Th1-type responses in mucosal leishmaniasis patients. Infect Immun. (2002) 70:6734-40. doi: 10.1128/IAI.70.12.6734-67 40.2002

119. de Carvalho Vivarini R, Pereira MS, Dias Teixeira KL, Calegari-Silva TC, Bellio M, Laurenti MD, et al. Human cutaneous leishmaniasis: interferondependent expression of double-stranded RNA-dependent protein kinase (PKR) via TLR2. FASEB J. (2011) 25:4162-73. doi: 10.1096/fj.11-185165

120. Skeiky Y, Benson DR, Guderian JA, Whittle JA, Bacelar O, Carvalho EM, et al. Immune responses of leishmaniasis patients to heat shock proteins of Leishmania species and humans. Infect Immun. (1995) 63:4105-14. doi: 10.1128/IAI.63.10.4105-4114.1995

121. Antonelli LR, Dutra WO, Almeida RP, Bacellar O, Carvalho EM, Gollob KJ. Activated inflammatory $\mathrm{T}$ cells correlate with lesion size in human cutaneous leishmaniasis. Immunol Lett. (2005) 101:226-30. doi: 10.1016/j.imlet.2005.06.004

122. Novais FO, Carvalho AM, Clark ML, Carvalho LP, Beiting DP, Brodsky IE, et al. CD8+ $\mathrm{T}$ cell cytotoxicity mediates pathology in the skin by inflammasome activation and IL-1 $\beta$ production. PLoS Pathog. (2017) 13:e1006196. doi: 10.1371/journal.ppat.1006196

123. Ivonise F, Cibele A, Olívia B, Clarissa BA, Lucas PC, Roque PA, et al. Epidemiologic and immunologic findings for the subclinical form of Leishmania braziliensis infection. Clin Infect Dis. (2002) 34:e54-8. doi: $10.1086 / 340261$

124. Novoa R, Bacellar O, Nascimento M, Cardoso TM, Ramasawmy R, Oliveira WN, et al. IL-17 and regulatory cytokines (IL-10 and IL27) in L. braziliensis Infection. Parasite Immunol. (2011) 33:132-6. doi: 10.1111/j.1365-3024.2010.01256.x

125. Bittar RC, Nogueira RS, Vieira-Gonçalves R, Pinho-Ribeiro V, Mattos MS, Oliveira-Neto MP, et al. T-cell responses associated with resistance to
Leishmania infection in individuals from endemic areas for Leishmania (Viannia) braziliensis. Memorias Insti Oswaldo Cruz. (2007) 102:625-30. doi: 10.1590/S0074-02762007005000069

126. de Hippólito DDC, Gomes AHS, Maia MM, da Silva Meira-Strejevitch C, Kanamura CT, Lindoso JAL, et al. Gene expression profile of cytokines produced in biopsies from patients with American cutaneous leishmaniasis. Acta Trop. (2019) 189:69-75. doi: 10.1016/j.actatropica.2018.09.022

127. Costa DL, Cardoso TM, Queiroz A, Milanezi CM, Bacellar O, Carvalho EM, et al. Tr-1-like CD4+ CD25-CD127-/lowFOXP3- cells are the main source of interleukin 10 in patients with cutaneous leishmaniasis due to Leishmania braziliensis. J Infect Dis. (2015) 211:708-18. doi: 10.1093/infdis/jiu406

128. Suzuki M, Yokota M, Ozaki S, Matsumoto T. Intranasal administration of IL-27 ameliorates nasal allergic responses and symptoms. Int Arch Allergy Immunol. (2019) 178:101-5. doi: 10.1159/000493398

129. Liu X, Li S, Jin J, Zhu T, Xu K, Liu C, et al. Preventative tracheal administration of interleukin-27 attenuates allergic asthma by improving the lung Th1 microenvironment. J Cell Physiol. (2019) 234:6642-53. doi: $10.1002 /$ jcp. 27422

Conflict of Interest: The authors declare that the research was conducted in the absence of any commercial or financial relationships that could be construed as a potential conflict of interest.

Copyright (c) 2020 Jafarzadeh, Nemati, Chauhan, Patidar, Sarkar, Sharifi and Saha. This is an open-access article distributed under the terms of the Creative Commons Attribution License (CC BY). The use, distribution or reproduction in other forums is permitted, provided the original author(s) and the copyright owner(s) are credited and that the original publication in this journal is cited, in accordance with accepted academic practice. No use, distribution or reproduction is permitted which does not comply with these terms. 